\title{
Acoustic Properties of Concrete Panels with Crumb Rubber as a Fine Aggregate Replacement
}

\author{
Niall Holmes \\ Technological University Dublin, niall.holmes@tudublin.ie \\ Alex Browne \\ Technological University Dublin \\ Christopher Montague \\ Technological University Dublin, chris.montague@tudublin.ie
}

Follow this and additional works at: https://arrow.tudublin.ie/engschcivart

Part of the Civil Engineering Commons, and the Construction Engineering and Management Commons

\section{Recommended Citation}

Holmes, N., Browne, A. \& Montague, C. (2014) Acoustic properties of concrete panels with crumb rubber as a fine aggregate replacement, Construction and Building Materials, Vol. 73, pp.195-204, doi:10.1016/ j.conbuildmat.2014.09.107

This Article is brought to you for free and open access by the School of Civil and Structural Engineering at ARROW@TU Dublin. It has been accepted for inclusion in Articles by an authorized administrator of ARROW@TU Dublin. For more information, please contact arrow.admin@tudublin.ie, aisling.coyne@tudublin.ie, gerard.connolly@tudublin.ie.

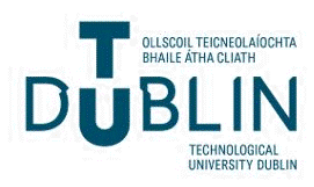




\section{ACOUSTIC PROPERTIES OF CONCRETE PANELS WITH CRUMB RUBBER AS A FINE AGGREGATE REPLACEMENT}

Niall Holmes*, Alex Browne, Christopher Montague

School of Civil \& Structural Engineering,

Dublin Institute of Technology,

Bolton Street,

Dublin 1,

Ireland.

Phone: +353 14022914

Email:niall.holmes@dit.ie

*Corresponding Author 


\begin{abstract}
This paper presents the acoustic performance of small scale crumb rubber concrete (CRC) panels in terms of the sound absorbance and insulation at low (63, 125, 250 \& $500 \mathrm{~Hz})$ and high $(1000,2000$, 4000 and $5000 \mathrm{~Hz}$ ) frequencies. Acoustic tests were conducted with differing levels of fine aggregate replacement with crumb rubber (7.5 and 15\%) with four different grades following freezing and heating. Analysis of the workability, compressive strength and density are also presented.
\end{abstract}

The results found that CRC performed well in terms of sound absorbance particularly with higher proportions (15\% here) and grades of crumb rubber. As an insulator, the CRC was comparable with plain concrete with only marginal differences observed. Effects of freezing and heating were shown to have no significant influence on the insulation properties. The insulation performance for all concretes was found to improve at high frequencies.

The results demonstrate that CRC has potential as an external building cladding to absorb sound around high-rise urban structures but requires full-scale testing on site. This approach offers an environmental friendly solution to the ongoing problem of used tyres.

KEYWORDS Crumb rubber concrete; acoustics; absorption; reflection; frequency 


\section{INTRODUCTION}

Noise pollution is an ongoing issue for inhabitants of urban and industrial areas but is often not adequately addressed by Building Regulations or Planning Authorities. Dense materials like concrete are often used as external cladding as a means to prevent the passage of sound transmission into the property by reflection. However, when sound waves strike concrete cladding panels for example, they are reflected away but are not reduced in magnitude and become problematic in enclosed spaces such as apartment complexes, factories and narrow streets (Figure 1). This can lead to a variety of problems such as masking warning signals, increasing the possibility of hearing loss and can be a factor in work-related stress [1, 2]. The city of Vancouver has published a noise control manual which outlines the issues with this challenge [3]. In it they outline the origins of urban noise, its problematic nature (like reflected sound between buildings) and what can be done to reduce it, including the use of sound absorbing and damping materials and vibration isolation. A study commissioned by the city showed the average noise levels for residences along a busy street ranged from 67-70dB over a 24hour period.

Lightweight materials such as foam or fabric are often too porous to reflect sound which passes through and its energy converted to heat with a reduction in magnitude. This approach is often used in cinemas and recording studios to reduce the reverberation time of the room. While effective internally, lightweight materials are not suitable externally so concrete is still the preferred material.

Each year 2-3 billion tyres are scrapped in the US with similar quantities in Europe. It is estimated that approximately 40 million tyres are discarded per year in the UK [4]. Ireland produces over 35,000 tonnes of waste tyres which are banned from many landfill sites and may not be burned [5]. With decreasing disposal options and increasing production, the volume of used tyres is becoming a major waste management issue. Stockpiled tyres lead to many health, environmental and economic risks through air, water and soil pollution, littering the landscape and represent a serious fire hazards as once set alight they emit harmful chemicals [4,5].

The use of crumb rubber concrete (CRC) produced from different sizes including fine (1-6mm) and course (6-19mm), of broken down waste tyres to replace a portion of natural aggregates in concrete mixes has been the subject of much research [4,6-13]. However, the literature shows that the use of CRC is impractical in many structural applications due to significant reductions in strength $[10,13-$ 15]. Despite the limited mechanical properties of CRC, there is a market for non-structural concrete 
products with medium to low strength requirements. Sound absorbing substances and barriers are frequently used as a way to mitigate ambient noise and make use of a recyclable waste product. CRC is a durable composite material capable of absorbing and reflecting sound [16] and if used on the exterior of a structure can shield the occupants from ambient street noise. High rise apartment occupiers for example are often overlooking busy streets with high noise levels, often uncomfortably high, passing into dwelling spaces.

This paper investigates the potential of CRC to improve the acoustic performance of small scale slabs. These findings have the potential to be incorporated into larger exterior building cladding systems (in the form of exterior panels as an absorbent material) to decrease noise transmission in urban or built up environments. 
Sound is a form of energy which travels through solids, liquids or gasses in longitudinal waves by vibrating particles oscillating in a body. These waves expand outwards with the intensity distributed over a larger area as it dissipates. The greater the particles vibrate within the medium, the more energy passes through it. There are two types of audible sounds; airborne and impact. Airborne sounds (speech, loudspeakers, musical instruments, etc.) cause waves to travel through the air but not solids. However, they produce vibrations within the structure which cause particles in the air on the opposite side to vibrate allowing them to be heard. Impact sounds (footsteps, closing doors, falling objects, etc.) vibrate through walls and floors and lead to airborne noise in adjacent rooms [17]. Noise and sound are often interchanged but are quite different with the former being subjective and dependant on the receptor. This concept of subjectivity is what many designers must take into account when considering noise in a structure, particularly in urban settings. As it is difficult to reduce the volume or production of sound in these environments, noise mitigation measures are often put in place to reduce the level of annoyance. Insulation, reflection or isolation methods along with dense barriers are better able to reflect sound energy where lighter materials can absorb noise and contain it.

The acoustic properties of concrete are defined as its ability to reduce the transmission of sound through it. The density of standard concrete mixes can, in relatively small thicknesses, provide sufficient mass to reflect sound. Previous research [18-20] has defined concrete as a good insulator which, due to its high density, can reflect up to $99 \%$ of sound energy [21]. However, plain concrete is a poor sound absorber which can lead to echoes within enclosed spaces.

\section{$2.1 \quad$ CRC acoustic properties}

The level of sound absorption is expressed as the absorption coefficient. An extremely dense material, which reflects $100 \%$ of sound away, has an absorption coefficient of 0 . Typical absorption coefficients for common construction materials are shown in Table 1.

Previous work has shown [22] that absorption coefficients for materials containing crumb rubber range from 0.3-0.7 which categorises it as a good absorber. Combining it with concrete has the potential of increasing the absorption qualities while reducing the level of reflected sound. Previous work in this area [19, 20, 22, 23] found sound absorption is improved with the inclusion of crumb rubber. 
Crumb rubber as a sound absorber for highways has been used in many parts of Arizona by incorporating it into bituminous mixes to reduce the noise produced by vehicular traffic. It is reported that over $80 \%$ of all asphalt in the state contains rubber asphalt accounting for roughly 12 million endof-life tyres [24]. Research [25] has shown that the sound absorption qualities of asphalt are significantly improved over time with the inclusion of crumb rubber in lightweight pavements due to greater energy absorption despite the well published reductions in compressive and tensile strength. This is supported by other work [26-28] who found the levels of vibration damping were $230 \%$ greater in CRC with a $15 \%$ replacement of fine aggregate compared to standard concrete.

Crumb rubber has also been added into concrete blocks producing a lighter, more flexible and durable absorbing material with a $20 \%$ fine aggregate substitute [29]. Investigations into the performance of CRC in different environments found that the use of air entraining admixtures increases the durability against freeze thaw action [30-33]. A study into the compressive behaviour of CRC subjected to excessive heat [15] $\left(25^{\circ} \mathrm{C}\right.$ to $\left.600^{\circ} \mathrm{C}\right)$ demonstrated a significant improvement in energy absorption particularly with smaller grades of rubber and lower fine aggregate replacements. Unlike regular aggregates such as sand \& gravel, crumb rubber is highly elastic and has the ability to temporarily deform under pressure and loading $[7,24]$ with ductility increases as much as $90 \%$ and corresponding enhanced energy dissipation.

Increased volumes of rubber result in reduced CRC densities. As material acoustic properties are largely dependent on its density, lighter ones (such as CRC with high levels of crumb rubber) will absorb more sound. This in turn will reduce the concretes ability to reflect sound energy [21-23]. CRC panels have the potential be used on office buildings as exterior cladding or on the perimeter of balconies due to its lightweight and energy absorbing qualities. The degree of compaction of CRC also influences sound absorption [23] as larger grades will absorb more when sufficiently compacted in concrete as a larger surface area of the rubber will be exposed. Concrete cladding panels are widespread due to the protection they offer to the structure from the elements, the high quality appearance and ease of placement. CRC cladding panels could also be used as an alternative to protect structures with the added advantage of reducing the overall weight. Figure 2 shows how the acoustic performance of a high-rise building could be improved by the application of exterior CRC panels particularly around balconies which also reduces the level of reflected noise. Similar proposals have been shown in [3]. 


\subsection{Mix Proportions}

The concrete cast for this study included one control mix incorporating only CEM I cement and a number of other mixes containing dust, $1-3 \mathrm{~mm}, 2-6 \mathrm{~mm}$ and $10-19 \mathrm{~mm}$ crumb rubber grades from a local supplier, Figure 3, with fine aggregate replacement levels of 7.5 and 15\%. A summary of the concrete cast is reported in Table 2. All of the mixes had a fixed water to cement (w/c) ratio of 0.47 and a cementitious material content of $475 \mathrm{~kg} / \mathrm{m}^{3}$. Following a number of trial mixes, the final proportions were determined so that a slump between 50-100mm (S1 class slump) [34] could be achieved. The mix proportions are summarised in Table 3.

\subsection{Materials}

CEM I cement complying with BS EN 197-1, Cement: Composition, Specifications and Conformity Criteria for Common Cements [35] was used as the cementitious material. Both the fine and coarse aggregates were obtained from local sources in Ireland. The fine aggregate used was medium graded sand and the coarse aggregate was crushed limestone with a maximum size of $20 \mathrm{~mm}$. Before mixing, the water absorption of the aggregates was determined and the water added to the concrete was adjusted accordingly to cater for this.

\subsection{Preparation of samples}

The concrete was manufactured using a pan mixer. For each mix in Table 1, 9 panels $(245 \times 245 \times 100 \mathrm{~mm})$ and 6 cubes $(100 \times 100 \times 100 \mathrm{~mm})$ were cast to determine the acoustic performance and compressive strength (at 7 and 28 days) respectively. Each mix had a volume of $0.078 \mathrm{~m}^{3}$ including $20 \%$ for wastage.

After mixing, the concrete was poured in 50mm thick layers, into the moulds with each layer vibrated on a vibrating table for a time until no more air bubbles were visible on the surface. Curing of the concrete was provided by placing a polythene sheet over the specimens for 24 hours to trap moisture that evaporates from the surface. Following demoulding, the samples were placed in water in a curing tank at $20( \pm 1)^{0} \mathrm{C}$ until they were tested. Figure 4 shows the stainless steel moulds (a) before and (b) after casting. 


\subsubsection{Workability}

The workability (i.e. consistence) of the concrete was measured immediately after its manufacture in terms of slump in accordance with BS EN 12350-2 for testing fresh concrete [36].

\subsubsection{Compressive strength}

The compressive strength was determined by crushing three $100 \mathrm{~mm}$ cubes at 7 and 28 days for each mix in accordance with BS EN 12390-3 for testing hardened concrete [37].

\subsubsection{Sound absorption}

The sound absorption coefficients were measured using the random incidence method where the reverberation time of a room was recorded with and without the samples present. As the conditions within the room remain constant any difference in sound absorption is directly related to the sample being present and can be calculated. The reverberation times here were calculated based on the average time from 10 tests with $\left(T_{1}\right.$, sec) and without $\left(T_{2}\right.$, sec) the sample. The room volume, $\left(\mathrm{V}, \mathrm{m}^{3}\right)$ and surface area $\left(\mathrm{A}, \mathrm{m}^{2}\right)$ of the sample were also measured.

The test was conducted by creating a sharp sound in the hard-surfaced room (Figure 5) which was recorded by the speakers on an Apple laptop using the free to download Audacity® acoustic software with time taken for the sound intensity to dissipate by $60 \mathrm{~dB}$ measured. The hard-surfaced laboratory was adjacent to an anechoic (non-echoing) chamber (Figure 5) which is completely insulated. The anechoic chambers walls and ceiling are covered with sound absorbent material (Figure 6) designed to absorb and scatter noise.

To calculate the random incidence absorption coefficient $(\alpha)$ of the concrete panels, the Sabine equation (Equation 1) was used, where c is the speed of sound in air $(343 \mathrm{~m} / \mathrm{s})$. Sabine acoustics makes the following assumptions:

- sound in the room is diffuse;

- the sound energy intensity is constant throughout;

- sound absorption is spread equally over the surfaces of the room;

- the dimensions of the room are similar and square shaped. 


$$
\alpha=\frac{55.3 \mathrm{~V}}{\mathrm{cSA}}\left(\frac{1}{\mathrm{~T}_{2}}-\frac{1}{\mathrm{~T}_{1}}\right)
$$

Equation 1

\subsubsection{Sound Insulation}

The sound insulation of the CRC was measured by recording the level sound intensity (dB) through the various concrete panels located in a duct between two rooms (Figure 5) using a range of low (63, 125, $250 \& 500 \mathrm{~Hz})$ and high $(1000,2000,4000$ and $5000 \mathrm{~Hz})$ frequencies using a Type 4224 Brüel and Kjaer sound source. A sound of $65 \mathrm{~dB}$ was generated in the hard-surfaced room which was recorded in the anechoic chamber after it passed through the concrete sample. The samples were placed into the duct (Figure 7(a)) and surrounded by a dense putty to reduce the transmission of sound around the sides of the sample (Figure 7(b)) and the above measurement repeated. The measured sound intensity $(\mathrm{dB})$ after it passed through the sample was recorded using a Brüel and Kjaer Type 2250 light microphone on a 1m high tripod (Figure 7(c)) to assess its insulation properties. The above was repeated ten times for each panel and the results averaged.

Three samples from each crumb rubber grade were tested before and after simulated adverse weathering conditions by heating in an oven at $75^{\circ} \mathrm{C}$ for 24 hours. Three more were tested following freezing for 24 hours at $-15^{\circ} \mathrm{C}$ with the remainder subject to normal laboratory conditions $\left(15 \pm 5^{\circ} \mathrm{C}\right)$ to assess the acoustic performance of CRC in these conditions as its improved durability in these environments has been previously reported [32, 38]. 


\section{RESULTS AND DISCUSSION}

\subsection{Workability}

The slump values are reported in Figure 8 which shows a decrease in workability with increasing crumb rubber grades and proportions. This is most likely due to the reduced 'flowability' of the larger particles which has been seen in previous work [30-33] which recommend using a higher w/c ratio for greater volumes of rubber in the mix. Decreases in slump from 125-25mm were reported [30] when the crumb rubber content increased from 0 to $120 \mathrm{~kg} / \mathrm{m}^{3}$. A similar trend can be seen here with an approximate drop of 50\% observed when compared to the control. Increases in slumps where also found [31] when smaller grades of rubber crumb was used as a fine aggregate replacement up to a maximum value of $15 \%$. However, it has also been shown $[39,40]$ that increasing the crumb rubber content in concrete resulted in decreased workability due to reduced inter-particle friction between the rubber and other mix constituents which also lowered the unit weight of the plastic mix.

Figure 8 also shows a noticeable drop in slump for mix 1E (7.5\% fine aggregate replacement, 2-6mm crumb rubber). It is believed this is due to the incorrect water content added to this particular mix which also had an effect on the compressive strength.

\subsection{Compressive strength}

The compressive strength results are presented in Figure 9. As shown (and as expected), there is a decrease in the strengths of all CRC samples. Also, for every grade size shown, the compressive strength is less in the $15 \%$ fine aggregate replacement levels than in the lower. Similar strength reductions were observed with the same fine aggregate replacement by crumb rubber [41]. While the compression strength of the control exceeds the characteristic strength $\left(35 \mathrm{~N} / \mathrm{mm}^{2}\right)$, the CRC did perform well with the majority of the mixes meeting or exceeding the design requirement at 28 days. It has been shown [40-43] that significant reductions in compressive strength can be avoided when the crumb rubber replacement level does not exceed $20 \%$ of the total aggregate content and minimised below $15 \%$.

It can be seen that the strength of mix $1 \mathrm{E}$ (7.5\% fine aggregate replacement, 2-6mm crumb rubber) was significantly higher than the others. This is believed to be due to two reasons. Firstly, as discussed above and seen in Figure 8, the water content for this mix was incorrect and lower than required. Secondly, upon further investigation, it was discovered that the crumb rubber in these cubes 
were not evenly distributed during mixing, as a consequence of the inadequate water content. Figure 10 demonstrates this uneven distribution compared with another cube with adequate dispersal. Rubber particles in concrete can migrate to the centre of test samples after vibration which can lead to nonuniform distribution with higher failure stress levels. As crumb rubber particles are hydrophobic, one might expect them to coagulate and flock together. This issue was not observed in any of the other cubes following crushing and may have been caused by inadequate compaction during vibration leading to the rubber particles not distributing properly.

\subsection{Density}

As shown in Figure 11, there is a decrease in density of the CRC samples compared with the control. This is due to the lower relative density of CRC than plain concrete with natural aggregates which has been previously observed [7, 9, 13, 24, 29] particularly when fine aggregates were replaced. CRC also has higher air contents than plain concrete $[25,44]$ which is confirmed here by the increased density of the 7.5\% fine aggregate replacement CRC's for every crumb rubber grade used. This reduced weight is desirable in a number of architectural applications including facades, precast elements and in concrete toppings on metal decks [43, 46].

\subsection{Sound absorption}

The sound absorption co-efficient's for the different CRC and plain concrete samples in the laboratory environment are shown in Figure 12. The absorption coefficient of the CRC ranges from 0.013 and 0.2 compared with 0.018 in the plain concrete which is similar to previous work in this area [7]. The results indicate that the level of absorption is greater for those concretes with higher volumes and larger grades of rubber. For instance, the $7.5 \%$ replacement of fine aggregate by dust yielded an absorption co-efficient of 0.013 compared to 0.018 from the control. However, as the size and volume of particles increase, the opposite is true as the larger surface area and heavier graded rubber is capable of absorbing more sound. For instance, there is an absorption coefficient increase of 623\%, $107 \%$, 33\% and $21 \%$ between the $7.5 \%$ and $15 \%$ replacement levels for the dust, $1-3 \mathrm{~mm}, 2-6 \mathrm{~mm}$ and $10-19 \mathrm{~mm}$ crumb rubber particles respectively. This increased absorption demonstrates that both volume and grading of rubber affect the CRC's acoustic absorbance properties.

The absorption co-efficient's for the panels following freezing and heating are shown in Figure 13. As may be seen, the general trends shown in Figure 12 are repeated demonstrating that irrespective of the environments, CRC maintains it absorption qualities. The results also indicate a slightly reduced 
absorption for the frozen than heated concretes which may be due to a thin ice layer forming at the surface which limits the sound absorbing capability of the concrete. However, this has a minor effect and compared with the control sample, the absorption quality remains high.

Investigations of the sound absorption properties of CRC panels with fine aggregate replacement levels of 10\%, 20\% and 30\% with low $(125,250$ and 500Hz) and high $(1000,2000$ and 4000Hz) frequencies [41] was found to have superior sound absorption properties than plain concrete particularly within the higher frequency range. The results from this study are shown in Figure 14 with the three grades of crumb rubber used namely No. 6 (passing ASTM sieve No. 6), No. 26 (passing ASTM sieve No. 26) and a combination of both, No. 6+26. The results demonstrate an improvement in absorbance with increasing frequency.

Density of a material is often considered to be the important factor that governs the sound absorption behaviour of the material. Previous studies showed an increase in sound absorption with higher frequencies and density. The addition of crumb rubber has been found $[41,44]$ to have a minor reduction in void content which is believed to be due to the impervious nature of crumb rubber which lowers the concretes porosity.

\subsection{Sound Insulation}

The results from the low and high frequencies sound insulating tests using the laboratory based slabs are shown in Figures 15 and 16 respectively. For the lower frequencies, the results indicate similar sound insulation properties with the control sample particularly at 63 and $125 \mathrm{~Hz}$ where the level of sound retained both is approximately 15 and $11 \mathrm{~dB}$ respectively. However, the control sample appears to be a slightly better insulator that the CRC at the higher frequencies (250 and $500 \mathrm{~Hz}$ ) with a 3-4dB improvement throughout due to the longer wavelengths allowing it to penetrate a larger surface area. Previous research [41, 44] has shown that higher density materials have improved insulation properties with the lower densities for all CRC's than the control (Figure 11). It is not surprising, therefore, that their insulating properties are poorer, albeit marginally.

The higher frequencies (Figure 16) have shown improved sound insulation properties for all concretes tested. As with the lower frequencies, the plain concrete is shown to be marginally better as an insulation material than CRC with an average of $5 \mathrm{~dB}$ improvement in sound retention for the 1000 , 2000 and $4000 \mathrm{~Hz}$ frequencies. However, the results are very similar at $8000 \mathrm{~Hz}$. 
The results indicate that while CRC has slightly reduced sound insulation properties than plain concrete, in combination with the improved absorptions seen in Figures 12-13, it can be effective in reducing noise in urban settings. It can also be seen that despite the higher densities in the heavier graded CRC, its sound reflective properties are similar to the lighter samples.

Figures 17 and 18 shows the insulation properties of the samples subjected to low and high sound frequencies respectively following freezing to $-15^{0} \mathrm{C}$. The results demonstrate no noticeable difference with the laboratory-based findings. One would expect a difference in results due to the creation of ice in the pore space which would accelerate the transmission of sound. Additional putty was required around the concrete to fill the gaps in the tunnel due to a minor reduction in volume due to freezing.

Similarly with the frozen samples, Figures 19 and 20 show little difference between the concrete insulation properties following heating to $75^{\circ} \mathrm{C}$. When concrete is heated it is subject to thermal expansion while its weight remains constant so its density per unit volume decreases with a corresponding increase in sound penetration per unit area. There is a minor decrease in insulation capacity for the $10-19 \mathrm{~mm}$ rubber grades which may have been due to some minor surface cracking observed in the concrete, as shown in Figure 21.

Previous work into the freezing and thawing of CRC [32,47] found with an increases in tyre rubber, the freezing and thawing durability decreased. The authors concluded that although CRC had higher air contents, the large-size and non-uniform distribution of trapped air voids might be a possible reason for their lack of improvement over plain concrete especially for higher proportions. The results here demonstrate that standard plain concrete perform better as an insulator in all environments albeit marginally with no significant difference with the CRC throughout. 
On the basis of the various investigations carried out to assess the acoustic performance of small scale CRC panels the following conclusions have been drawn:

(1) CRC has been found to be more effective than plain concrete in absorbing sound in low, normal and high temperature environments. Better absorption co-efficients were observed for higher rubber replacement levels (15\% here) and grades (2-6 mm \& $10-19 \mathrm{~mm})$. This is due to the higher densities of these concretes which is an important factor governing sound absorption behaviour.

(2) CRC performance as an insulator was comparable to plain concrete with marginal differences between both. It has shown here that all concretes perform better as an insulator for higher frequency sound due to the wider surface affected. As with the absorption study, there was no noticeable difference in insulation behaviour in the three environments. However, in conjunction with the improved sound absorbance, the results demonstrate CRC can be effective in reducing noise in urban settings. A minor decrease in the insulation performance of CRC in the elevated temperature was observed on the largest rubber grade $(10-19 \mathrm{~mm})$ due to some minor cracking on the surface.

(3) The workability of the concrete was decreased as the crumb rubber grade and proportion increased and reduced the 'flowability'. As expected, the compressive strength of the CRC was decreased for every grade and particularly for the higher replacement levels. However, the majority of the CRC did exceed the characteristic strength and previous work has shown that compressive strengths can be maintained provided the replacement level does not exceed 20\%. Uneven distribution of the crumb rubber in one sample was found to be due to an inadequate water content and vibration.

(4) The density of the CRC was found to be lower than the plain concrete. This is due to the higher air contents and reduced relative densities of the crumb rubber than natural aggregates, particular when fine aggregates have been replaced. 
The authors wish to acknowledge the Funding provided by Enterprises Ireland's Innovation Partnership programme which provided the financial support for this work. The authors also thank the technical support and the facilities of the School of Civil \& Structural Engineering in DIT Bolton Street and gratefully acknowledge Crumb Rubber Ireland Ltd. 


\section{REFERENCES}

[1] World Health Organisation (1997), Prevention of noise-induced hearing loss, Report of an informal consultation, Series 3: Strategies for Prevention of Deafness and Hearing, Geneva

[2] SIHI study group (1999), University of Maastricht

[3] City of Vancouver Noise Control Manual, Wakefield Acoustics Ltd.

[4] Mavroulidou, M. and Figueiredo, J. (2010) Discarded tyre rubber as concrete aggregate: A possible outlet for used tyres, Global NEST Journal, Vol 12 (4), pp 359-367.

[5] Department of the Environment, Community and Local Government. (2007). Waste Tyres.

[6] Eldin, N.N. and Senouci, A.B. (1993) Rubber-tired Particles as Concrete Aggregate, Journal of Materials in Civil Engineering, 5(4), 478-496.

[7] Fedroff, D., Ahmad, S., and Savas, B.Z. (1996) Mechanical Properties of Concrete with Ground Waste Tire Rubber, Transportation Research Record, 1532, 66-72.

[8] Schimizze, R.R., Nelson, J.K., Amirkhanian, S.N. and Murden, J.A. (1994) Use of waste rubber in light-duty concrete pavements, Proceedings of the Third Material Engineering Conference, Infrastructure: New Materials and Methods of Repair, San Diego, CA, 367-374.

[9] Biel, T.D. and Lee, H. (1994) Use of Recycled Tire Rubbers in Concrete, Proceedings of the Third Material Engineering Conference, Infrastructure: New Materials and Methods of Repair, p351-358.

[10] Toutanji, H.A. (1996) Use of rubber tire particles in concrete to replace mineral aggregates, Cement \& Concrete Composites, 18 (2), 135-139.

[11] Fedroff, D., Ahmad, S. and Savas, B.Z. (1997) Freeze-Thaw Durability of Concrete with Ground Waste Tire Rubber, Transportation Research Record, 1574, 80-88.

[12] Lee, H.S., Lee, H., Moon, J.S. and Jung, H.W. (1998) Development of tire-added latex concrete, ACI Materials Journal, 95 (4). 356-364.

[13] Li, Z., Li, F. and Li, J. (1998) Properties of concrete incorporating rubber tyre particles, Magazine of Concrete Research, 50 (4), 297-304.

[14] Ling, T. (2011). Prediction of density and compressive strength for rubberized concrete blocks, Construction and Building Materials, 25(11), 4303-4306.

[15] Guo, Y.-c., Znang, J.-h., Chen, G.-m., \& Xie, Z.-h. (2014). Compressive behaviour of concrete structures incorporating recycled concrete aggregates, rubber crumb and reinforced with steel fibre, subjected to elevated temperatures. Journal of CLeaner Production , In Press.

[16] Paje, S.E., Bueno, M. Terán, F. Miró, R, Pérez-Jiménez, F. and Martínez, A.H. (2010) Acoustic field evaluation of asphalt mixtures with crumb rubber, Applied Acoustics 71, 578-582.

[17] Bies, D.A. and Hansen, C. H. (2009) Engineering Noise Control, - Theory and Practice, Spon Press

[18] Celik, O.N. and Atis, C.D. (2008). Compactibility of hot bituminous mixtures made with crumb rubber-modified binders. Construction and Building Materials, Vol. 22(6), pp. 1143-1147.

[19] Seddeq, H.S (2009). Factors Influencing Acoustic Performance of Sound Absorptive Materials, Australian Journal of Basic and Applied Sciences, 3(4), pp. 4610-4617.

[20] Schwob, M. (2010). Sound Absorbers vs Sound Barriers. Retrieved March 2014, from Michael Schwob : http://michaelschwob.com/sound-absorbers-vs-sound-barriers/.

[21] Asdrubali, F.; D‘Alessandro, F.; Schiavoni, S. (2008). Sound absorbing properties of materials made of rubber crumbs. In Acoustics. 
[22] Asdrubali, F.; Baldinelli, G.; D“Alessandro, F. (2007). Evaluation of the acoustic properties of materials made from recycled tyre granules. In Proceedings of the 36th International Congress and Exhibition on Noise Control Engineering, Istanbul.

[23] Swift, M. B. (1999). Acoustic absorption in recycled rubber granulate. Applied Acousitcs, 57(3), 203-212.

[24] Kaloush, K. E., Way, G. B., \& Zhu, H. (2004). Properties of crumb rubber concrete. Arizona State University, Civil \& Environmental Engineering.

[25] Ling, T.C, Nor., H. M and Lim, S. K (2010) Using recycled waste tyres in concrete paving blocks, Proceedings of the ICE - Waste and Resource Management, Volume 163, Issue 1, 3745.

[26] Sukontasukkul, P., Chaikaew, C. (2006). Properties of concrete pedestrian block mixed with crumb rubber. Construction \& Building Materials, 20 (7), 450-457.

[27] Arizona Department of Environmental Quality (http://www.azdeq.gov/environ/waste/solid/tires.html).

[28] Ballie, M. and Gal, J (2000). Noise reduction induced by use of very thin wearing courses and crumb rubber particles, Proceedings of Inter-noise, Nice, France.

[29] Hamoush, S., Abu-Lebdeh, T., Picornell, M., \& Salah, A. (2011, October). Development of sustainable engineered stone cladding for toughness, durability and energy conservation. Construction and Building Materials, 25(10), 4006-4016.

[30] Kaloush, K.E., Way, G.B and Zhu, H (2006) Properties of Crumb Rubber Concrete, Transportation Research Record, Vol. 1914, pp. 8-14.

[31] Bignozzi, M.C and Sandrolini, F (2006) Tyre rubber waste recycling in self-compacting concrete, Cement and Concrete Research, Vol. 36 (4), 2006, pp. 735-739.

[32] Richardson, A. E., Coventry, k. A., \& Ward, G. (2012). Freeze/thaw protection of concrete with optimum rubber crumb content. Journal of Cleaner Production, 23(1), 96-103.

[33] Najim, K. and Hall, M. (2013). Crumb rubber aggregate coatings/pre-treatments and their effects on interfacial bonding, air entrapment and fracture toughness in self-compacting rubberised concrete (SCRC), Materials and Structures, 46(12), 2029-2043.

[34] BS EN 206 Part 1, Concrete: Specification, performance, production and conformity, British Standard Institute, 2000.

[35] BS EN 197-1, Cement: Composition, Specifications and Conformity Criteria for Common Cements, British Standards Institution, London, 2000.

[36] BS EN 12350-2, Testing fresh concrete. Slump-test, 2009.

[37] BS EN 12390-3, Testing hardened concrete. Compressive strength of test specimens, 2009.

[38] Savas, B. Z., Ahmad, S., and Fedroff, D. (1996). Freeze-Thaw Durability of Concrete with Ground Waste Tire Rubber, Transportation Research Record No. 1574, pp. 80-88.

[39] Güneyisi, E., Gesoğlu, M. and Özturan, T (2004) Properties of rubberized concretes containing silica fume, Cement and Concrete Research, Vol. 34 (12), pp. 2309-2317.

[40] Khatib, Z.K. and F.M. Bayomy, 1999. Rubberized Portland cement concrete. J. Mater. Civil. Eng. ASCE, 11: 206-213.

[41] Khaloo, A.R, Dehestani, M. and Rahmatabadi, P (2008). Mechanical properties of concrete containing a high volume of tire-rubber particles, Waste Management, Vol. 28 (12), pp. 24722482.

[42] Khalid, H.A and Artamendi, I (2004) Mechanical properties of used-tyre rubber, Proceedings of the ICE - Engineering Sustainability, Vol. 157 (1), pp. 37 -43. 
[43] Siddique R. and Naik T.R. (2004), Properties of concrete containing scrap-tyre rubber - an overview, Waste Management, 24(6), 563-569.

[44] Sukontasukkul, P. (2009). Use of crumb rubber to improve thermal and sound properties of precast concrete panel. Construction and Building Materials, 23(2), 1084-1092.

[45] Koizumi, T. (2002) The development of sound absorbing materials using natural bamboo fibers and their acoustic properties, Proceedings of Inter-noise. Dearborn.

[46] Holmes, N., Dunne, K. and McDonnell, J. (2014), Longitudinal Shear Resistance of Concrete Slabs containing Rubber Crumb Concrete, Journal of Construction and Building Materials, 55, 365-378.

[47] Richardson, A., Coventry, K. Dave, U. and J. Pienaar, J. (2004), Freeze/thaw performance of concrete using granulated rubber crumb, Journal of Green Building, Vol. 6, No. 1, pp. 83-92. 


\section{LIST OF FIGURES}

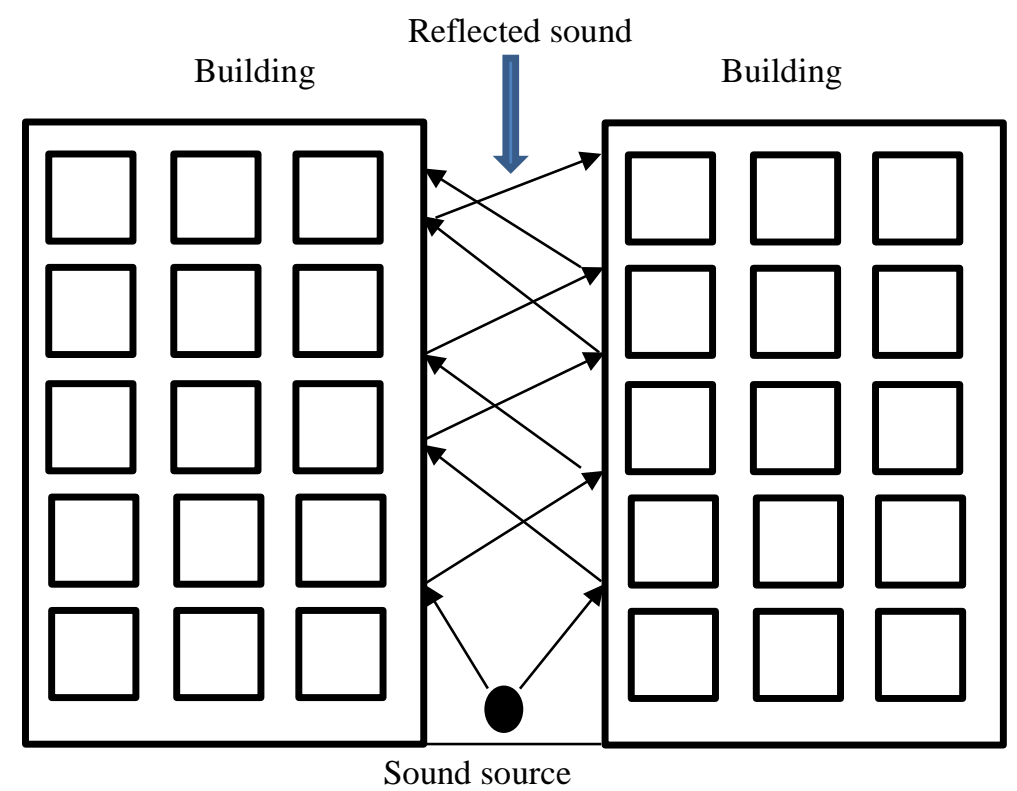

Figure 1 Reflections of sound waves in an enclosed narrow street 


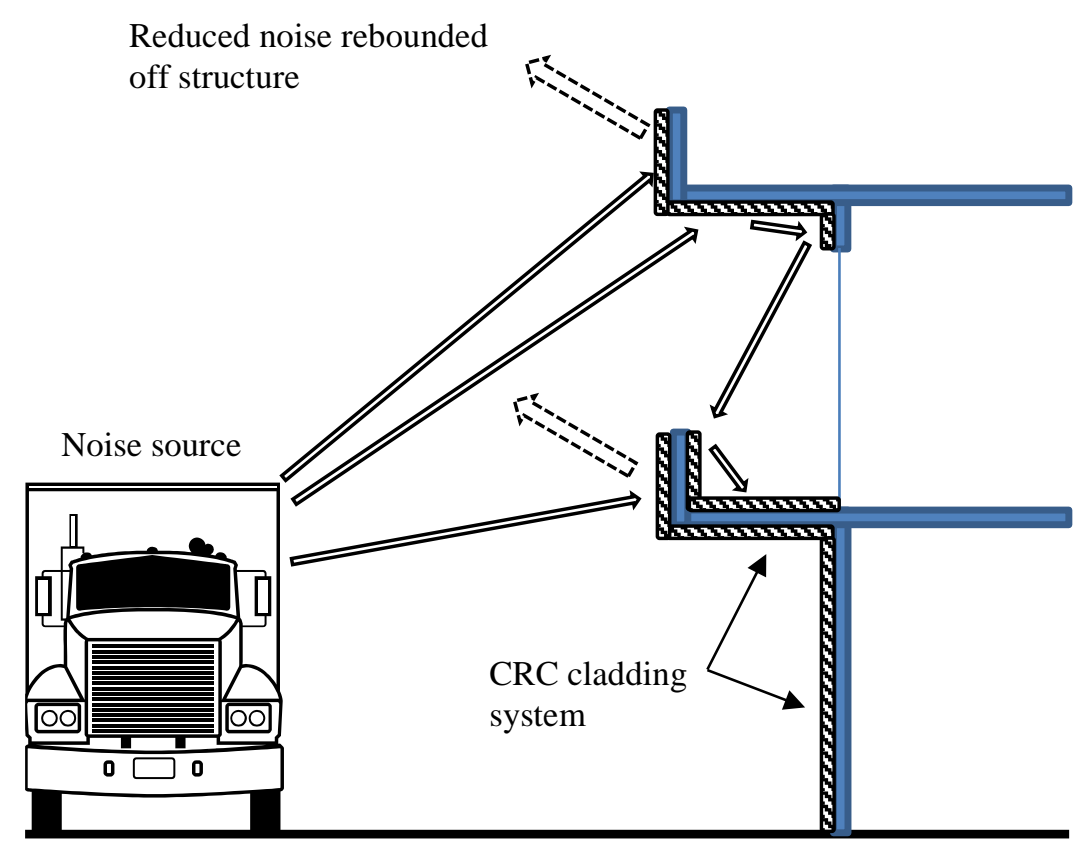

Figure 2 Example applications of a CRC cladding system on high rise structures to limit the transmission of sound into inhabitants (taken from [3]) 


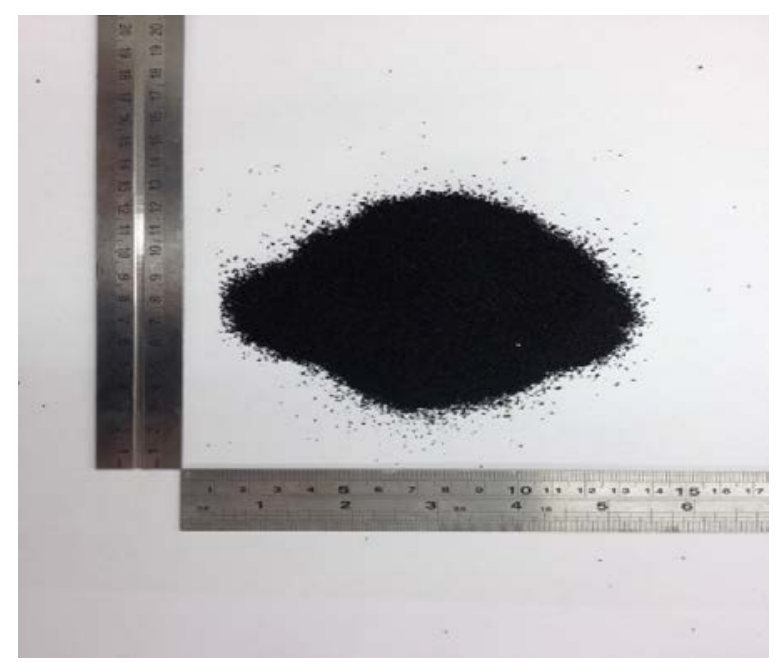

(a) Dust $(<1 \mathrm{~mm})$

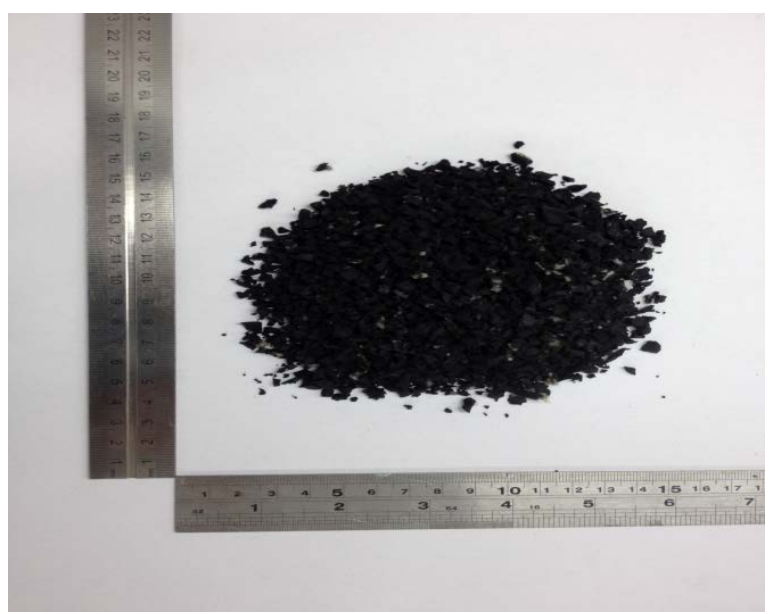

(c) $2-6 \mathrm{~mm}$

Figure 3 Different crumb rubber sizes used

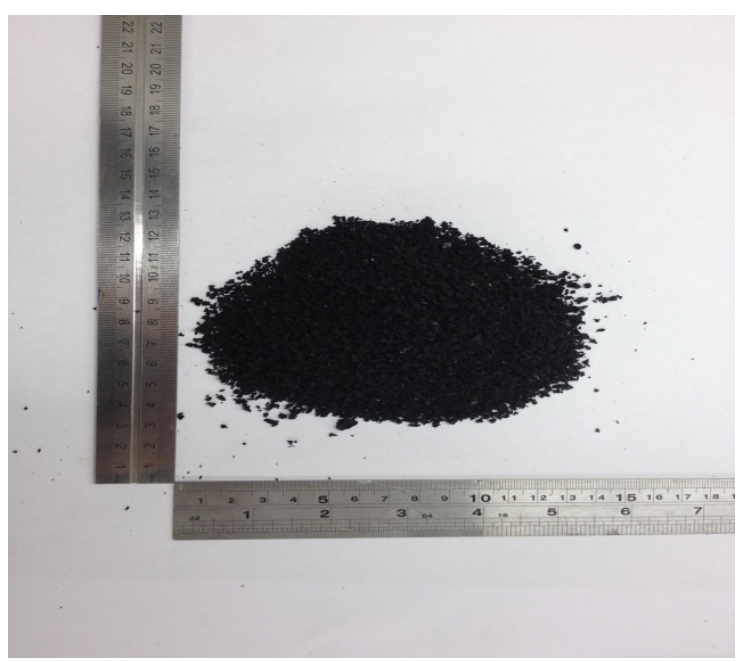

(b) $1-3 \mathrm{~mm}$

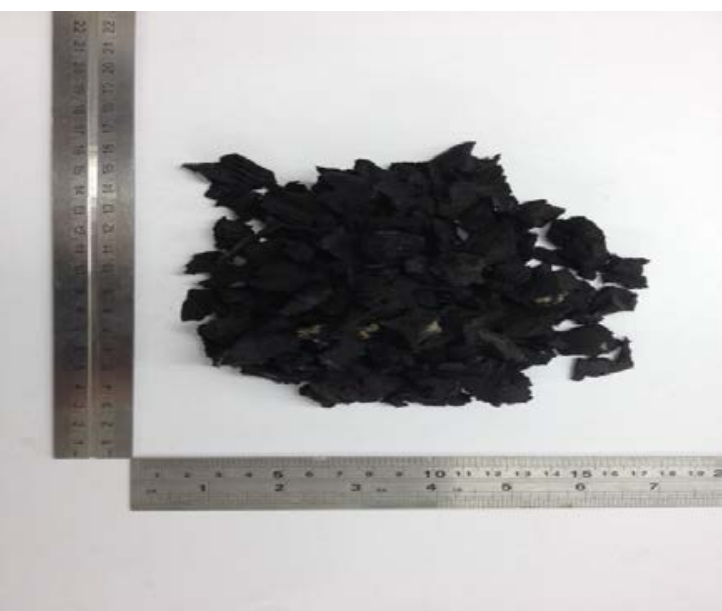

(d) $10-19 \mathrm{~mm}$ 


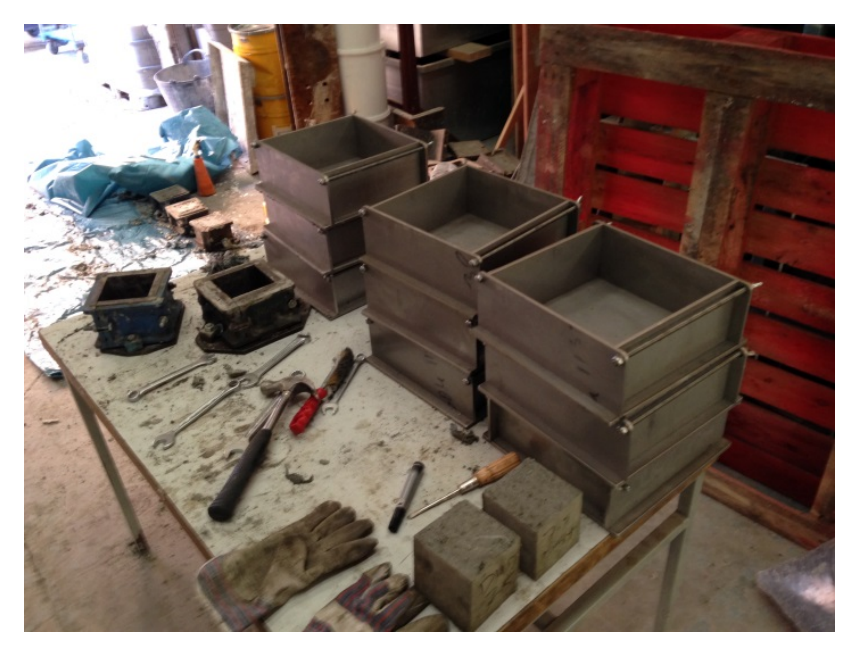

(a)

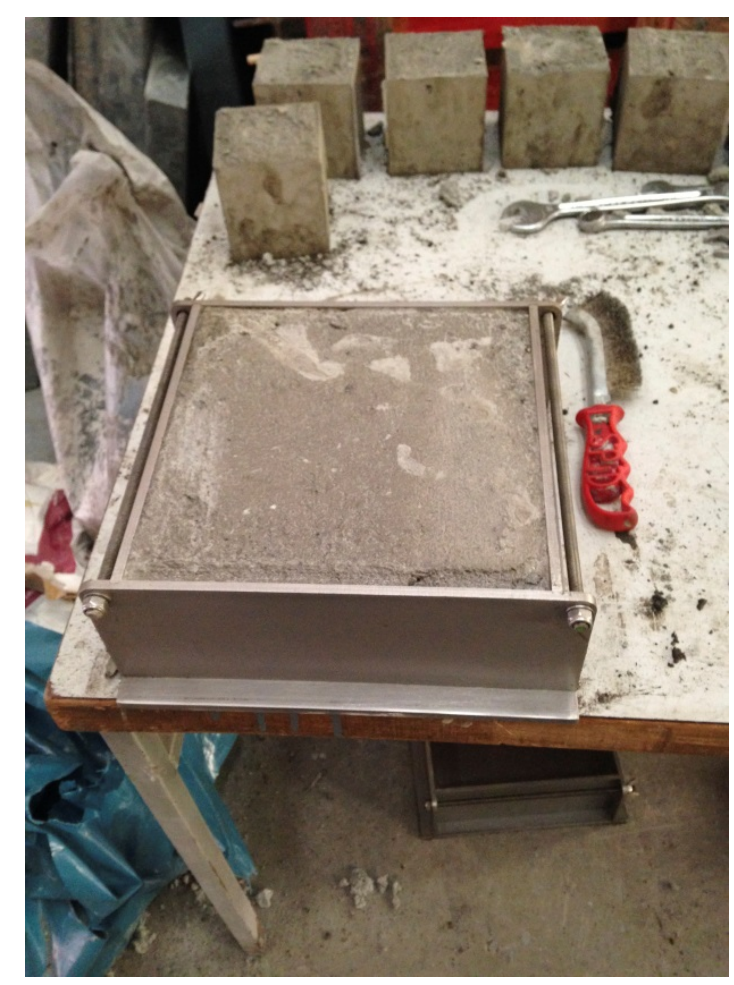

(b)

Figure 4 Preparation of the mould and concrete before (a) and after (b) casting 


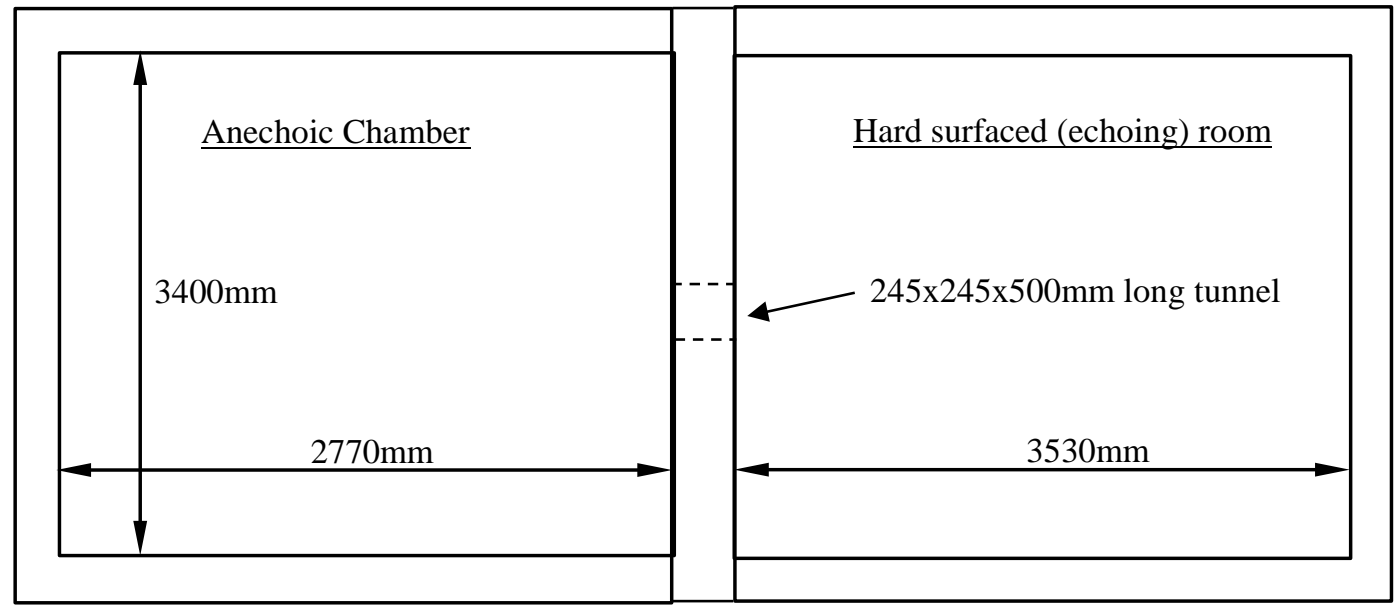

Figure 5 Plan of acoustic laboratory 


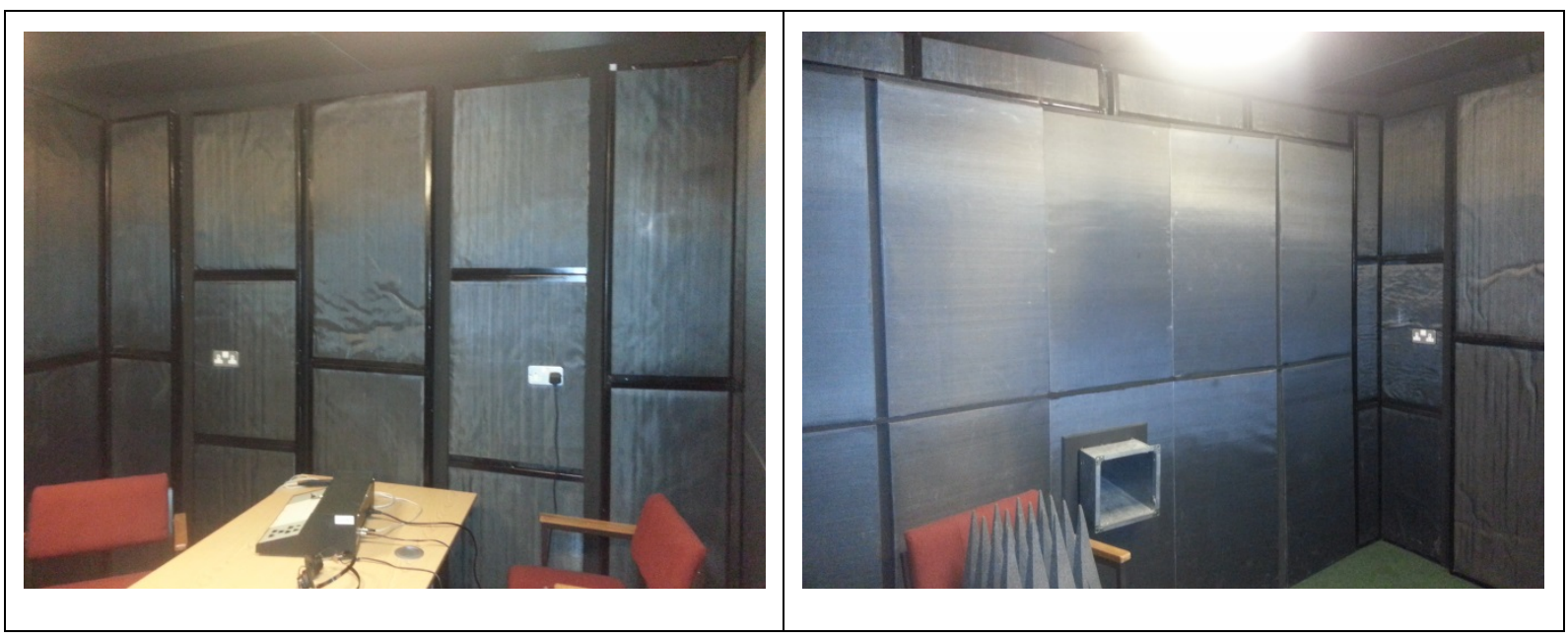

Figure 6 Anechoic chamber 


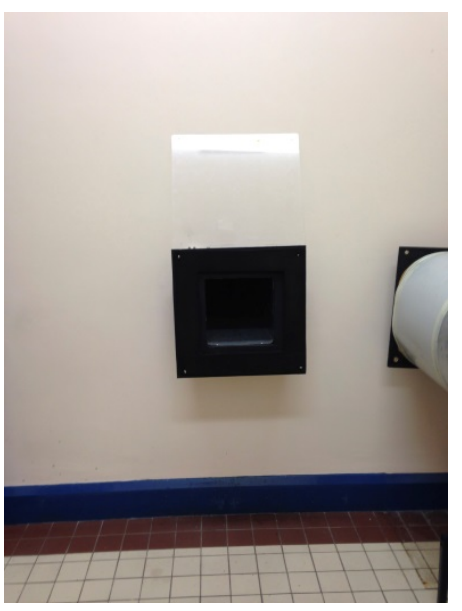

(a)

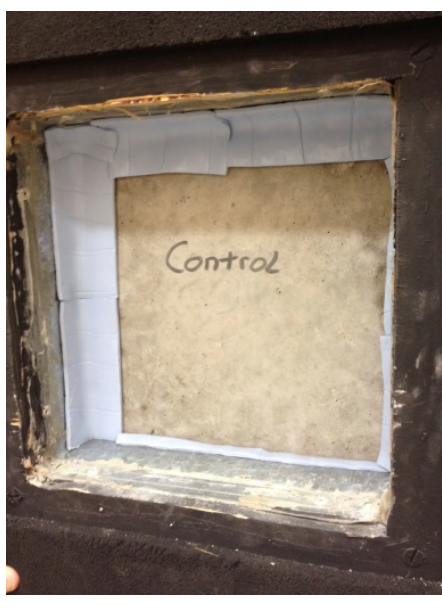

(b)

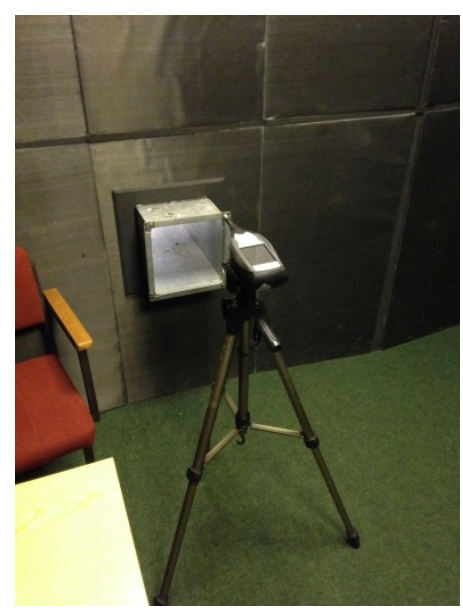

(c)

Figure 7

Sound insulation apparatus 


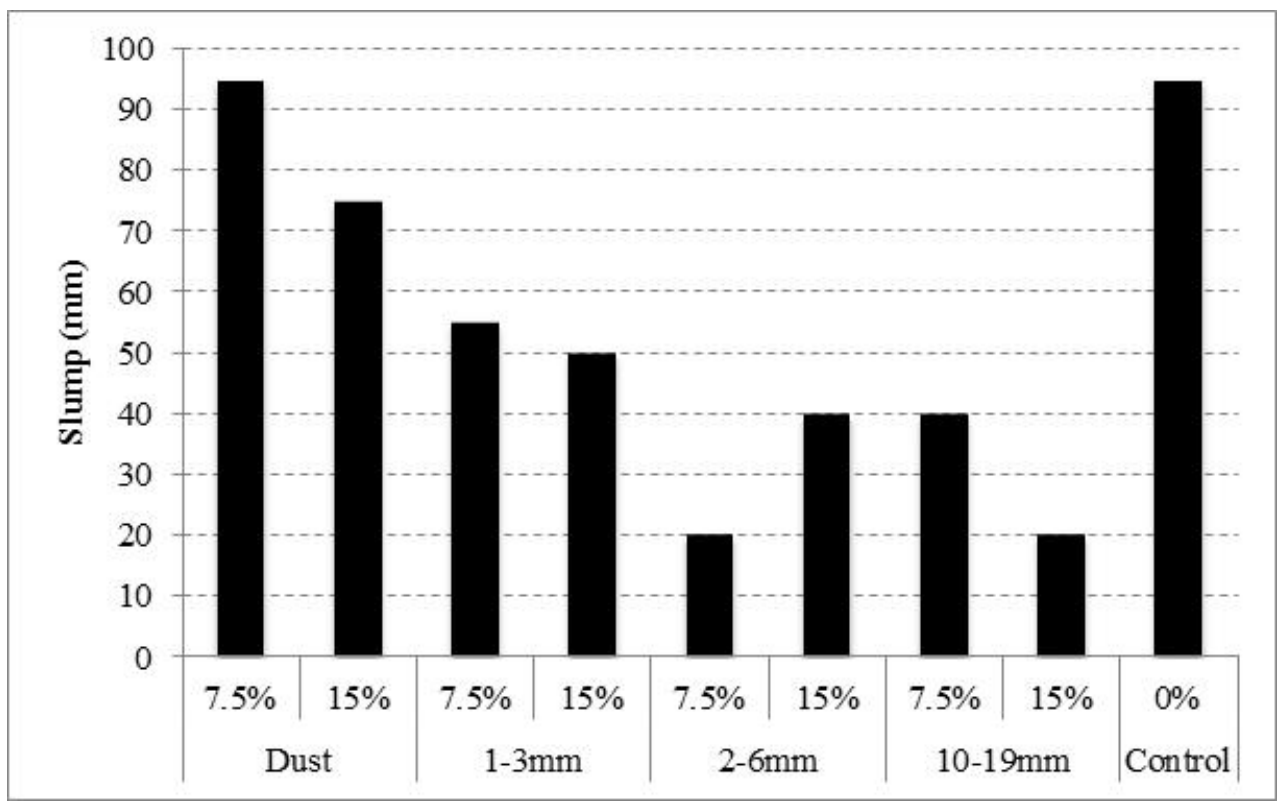

Figure 8 Slump values 


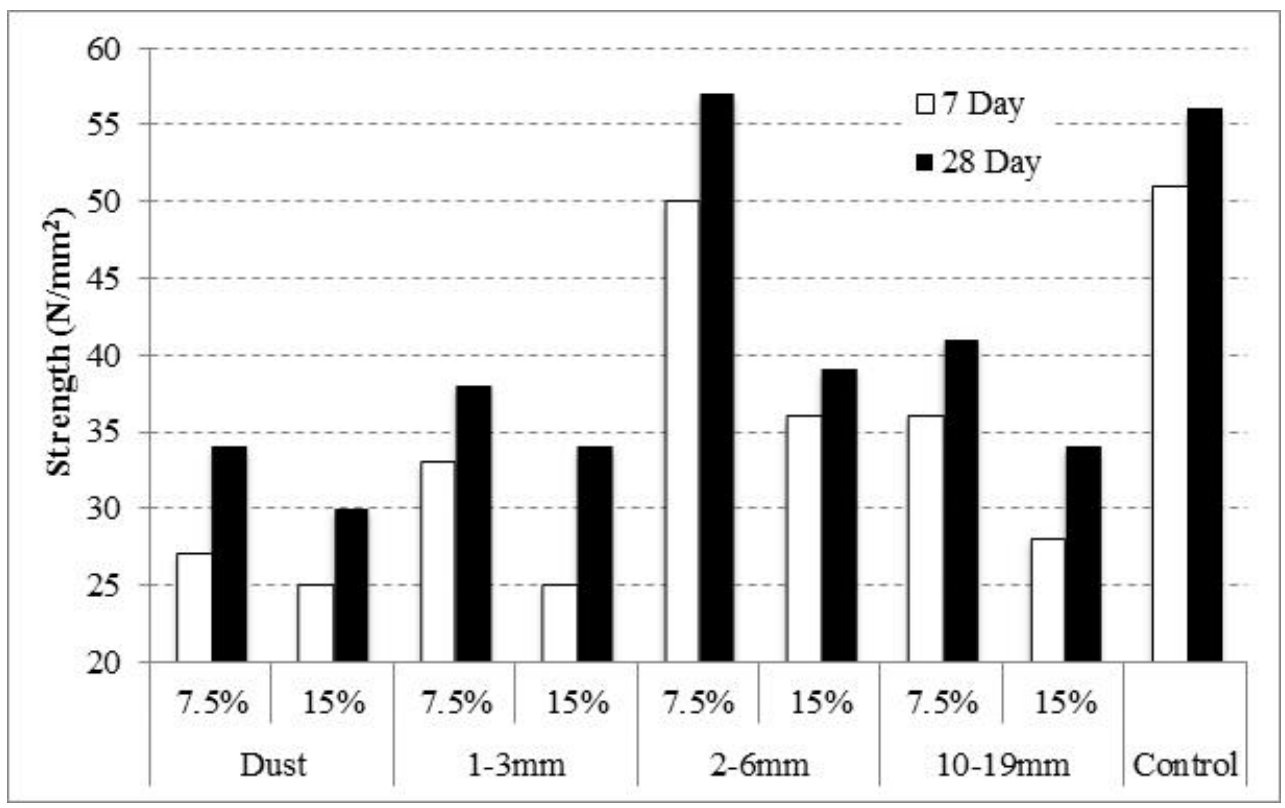

Figure 9 Compressive strength results 


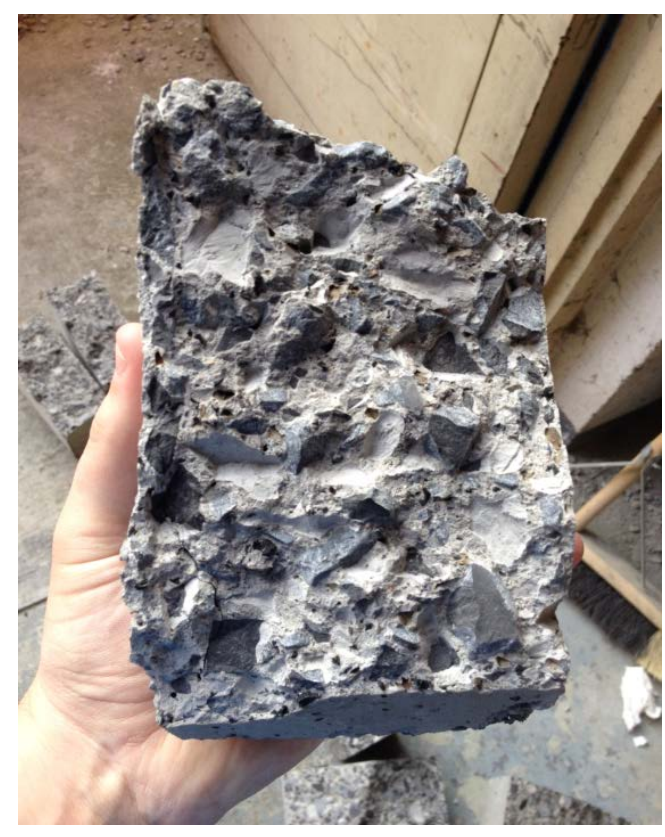

(a)

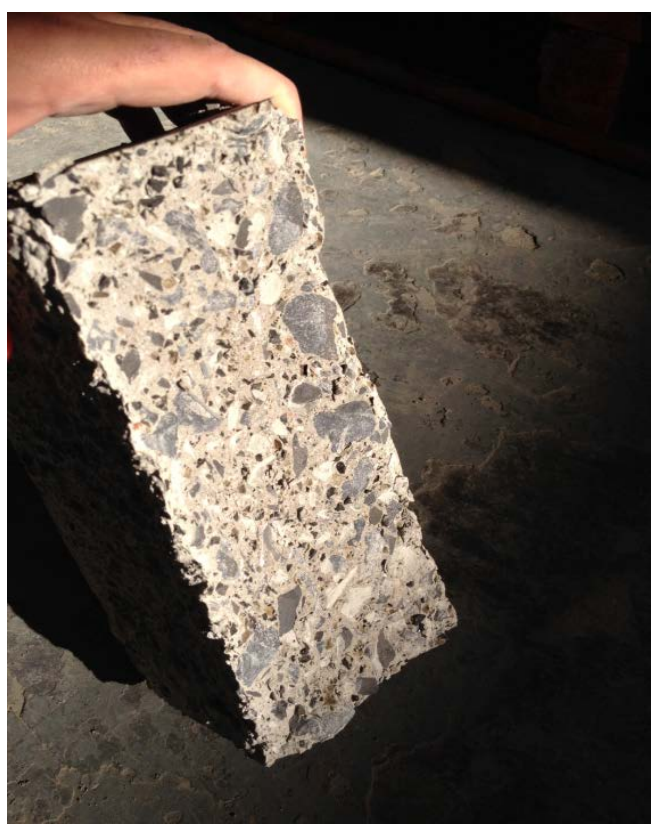

(b)

Figure $10 \quad 2-6 \mathrm{~mm}$ CRC with 7.5\% fine aggregate replacement levels showing (a) poor and (b) good distribution 


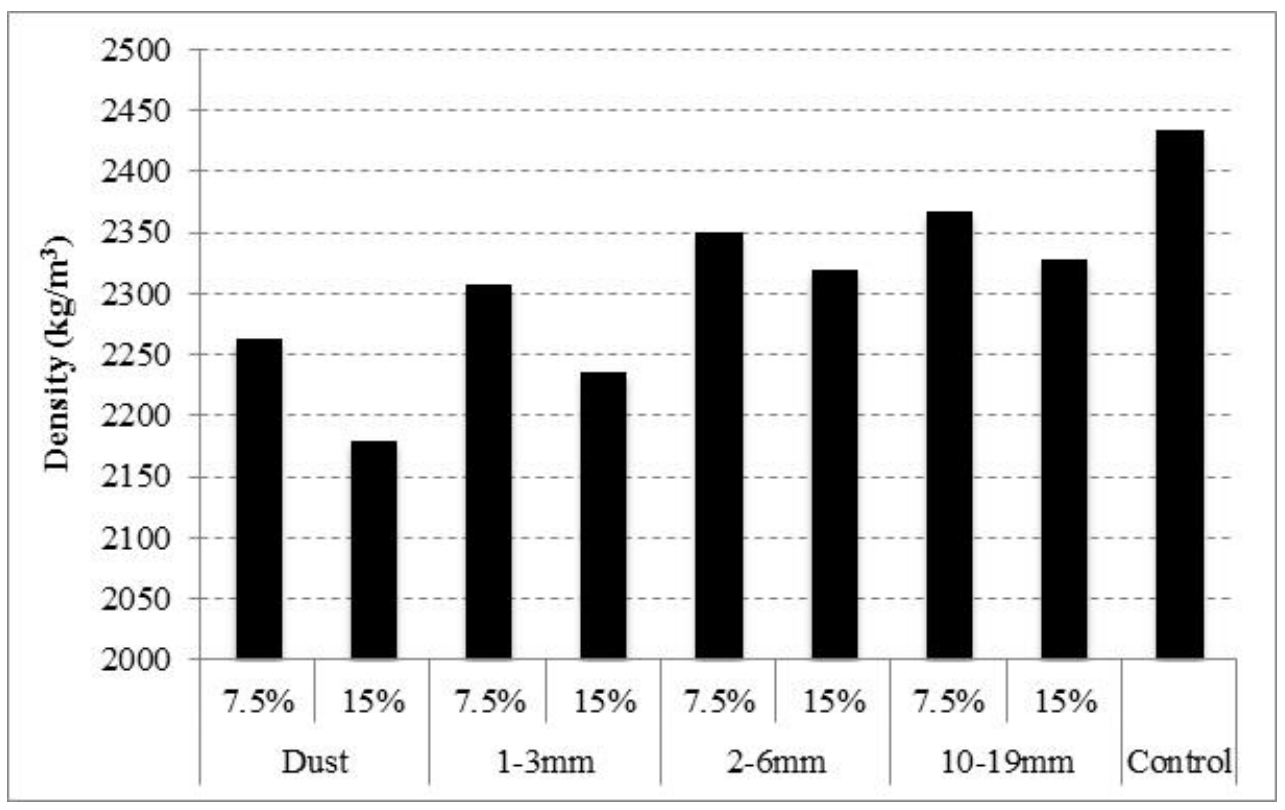

Figure 11 Density values 


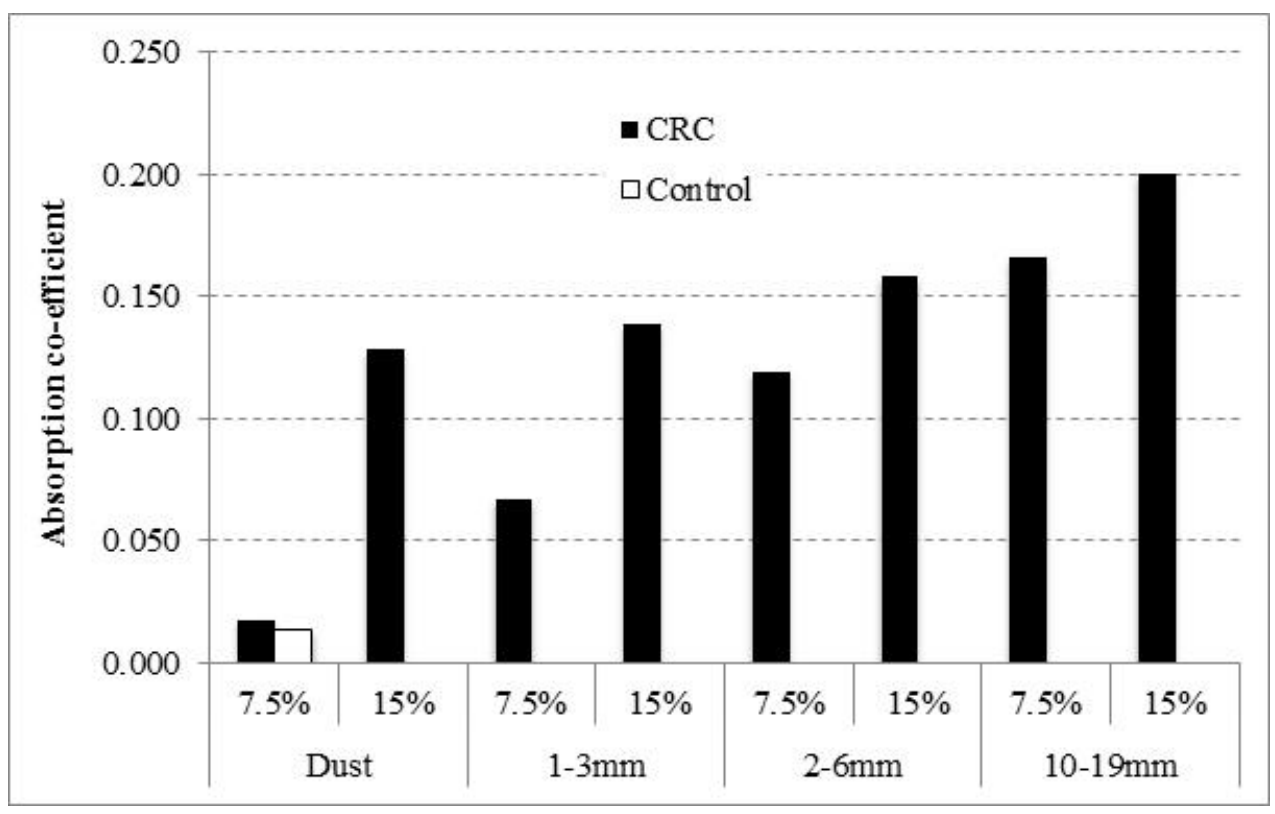

Figure 12 Sound absorption co-efficients for CRC and plain concrete 


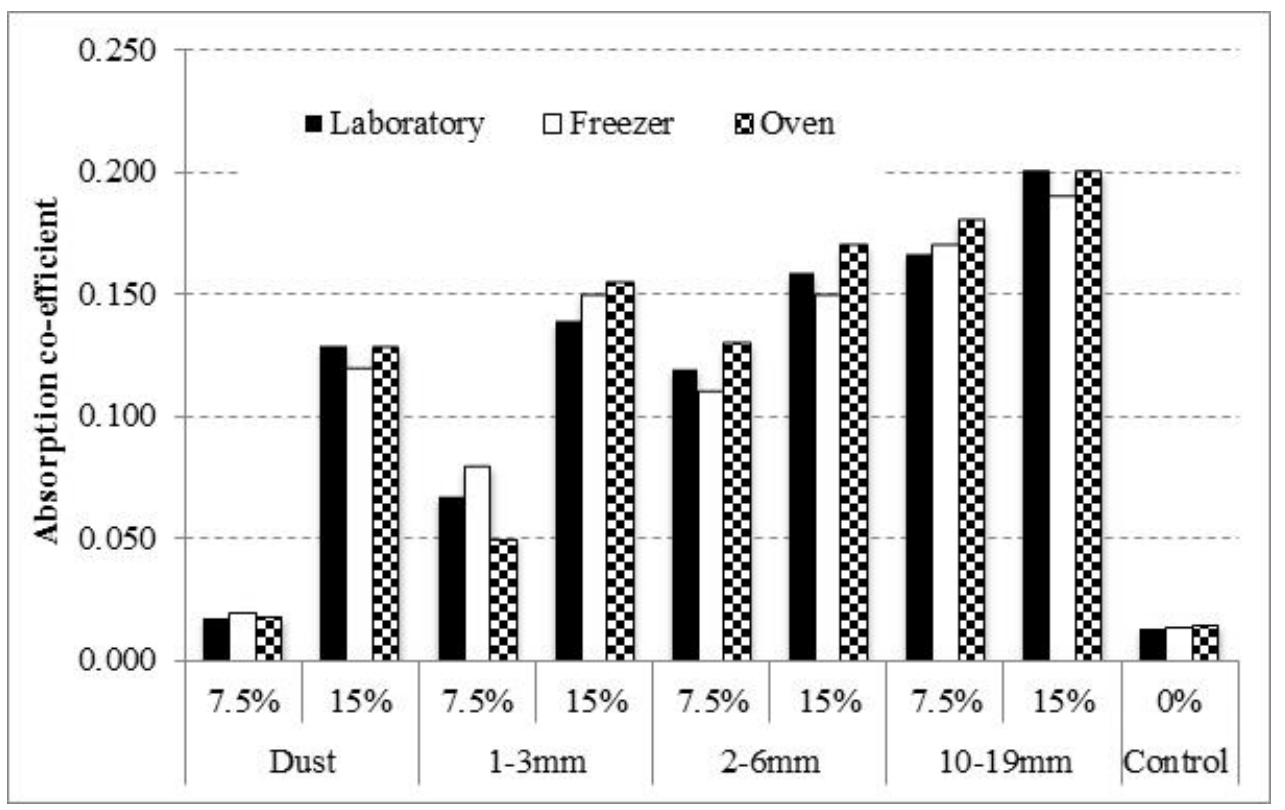

Figure 13 Sound absorption co-efficients for CRC and plain concrete following heating and cooling 


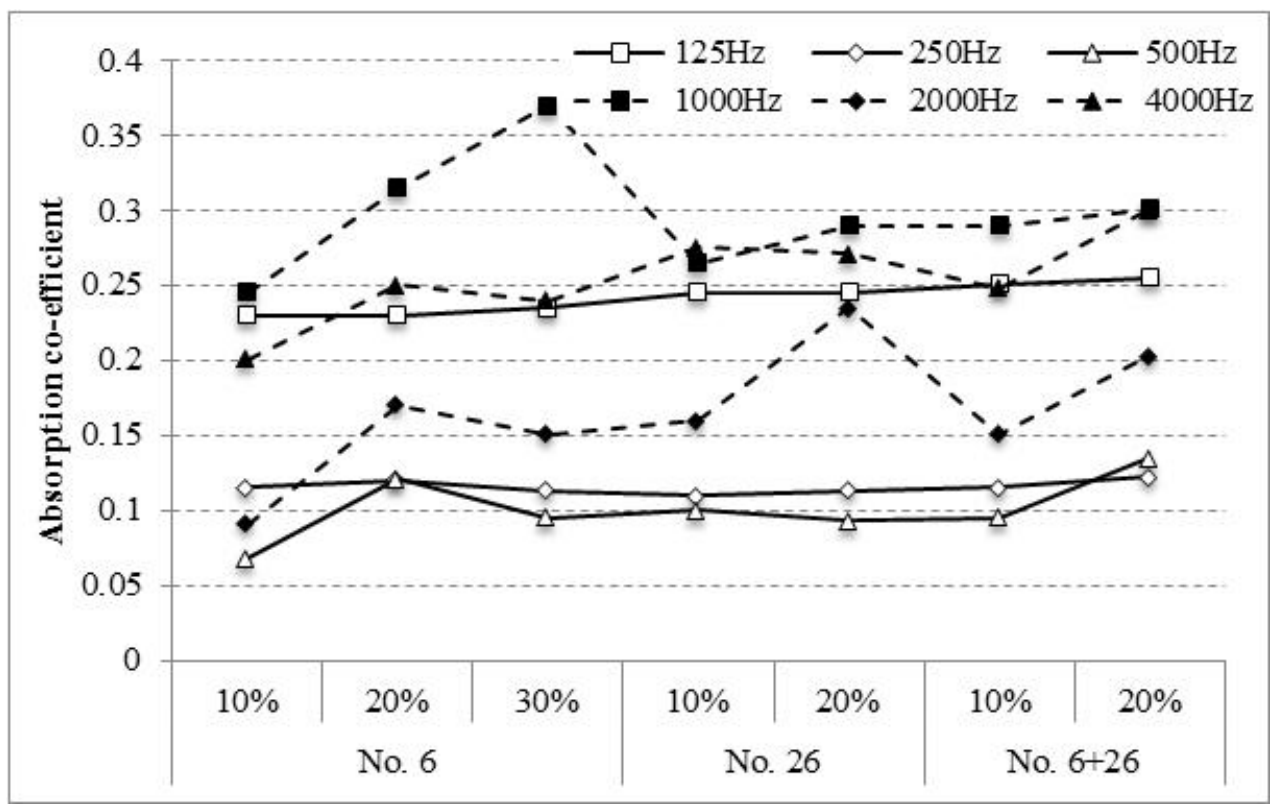

Figure 14 Sound absorption coefficient of crumb rubber concrete panel [41] 


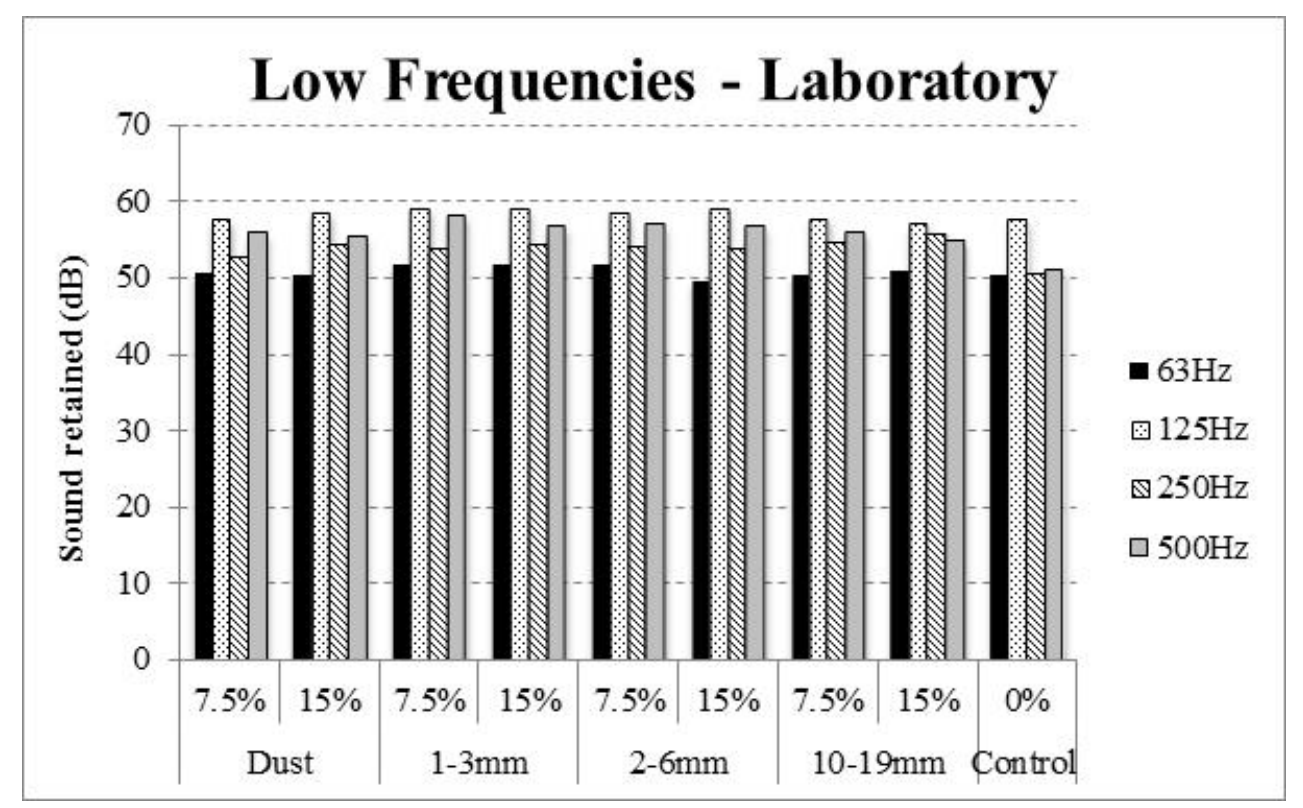

Figure 15 Sound insulating results with low frequencies $(63,125,250$ and 500Hz) in laboratory conditions 


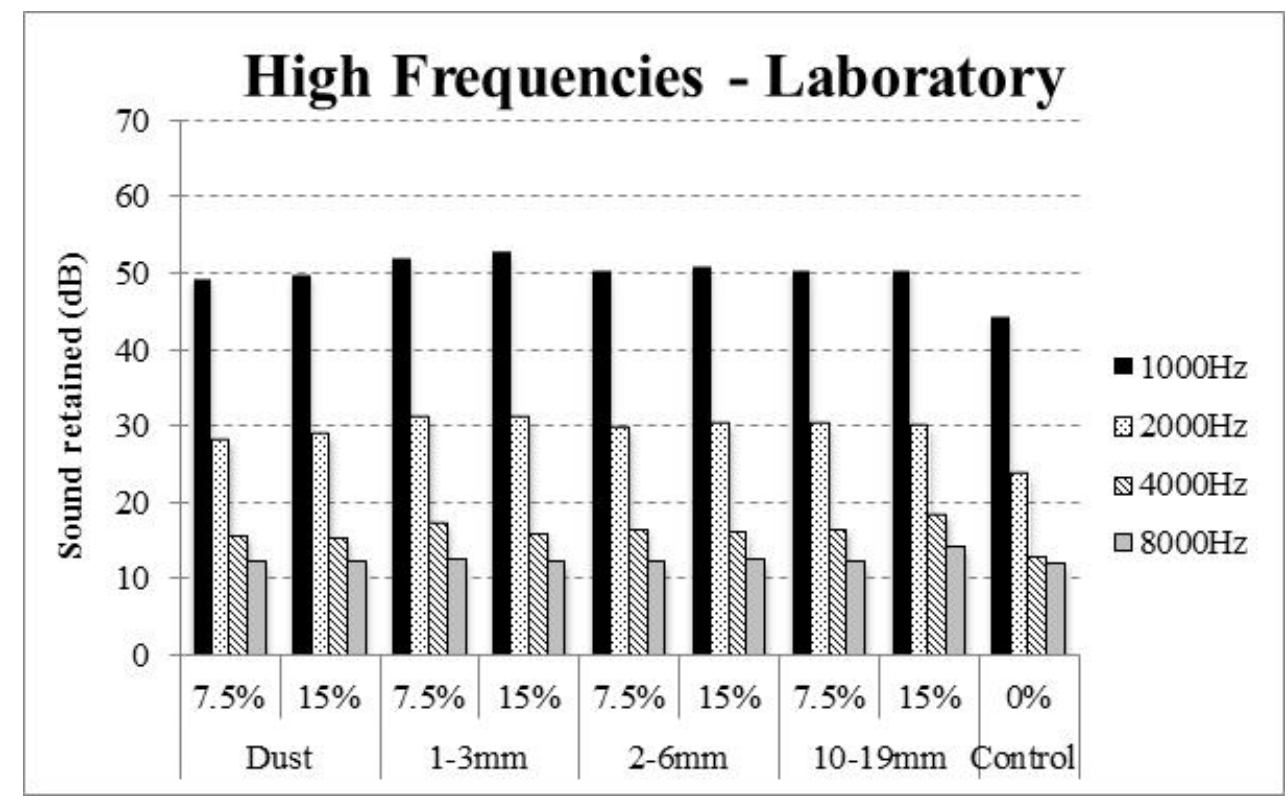

Figure 16 Sound insulating results with high frequencies (1000, 2000, 4000 and $8000 \mathrm{~Hz})$ in laboratory conditions 


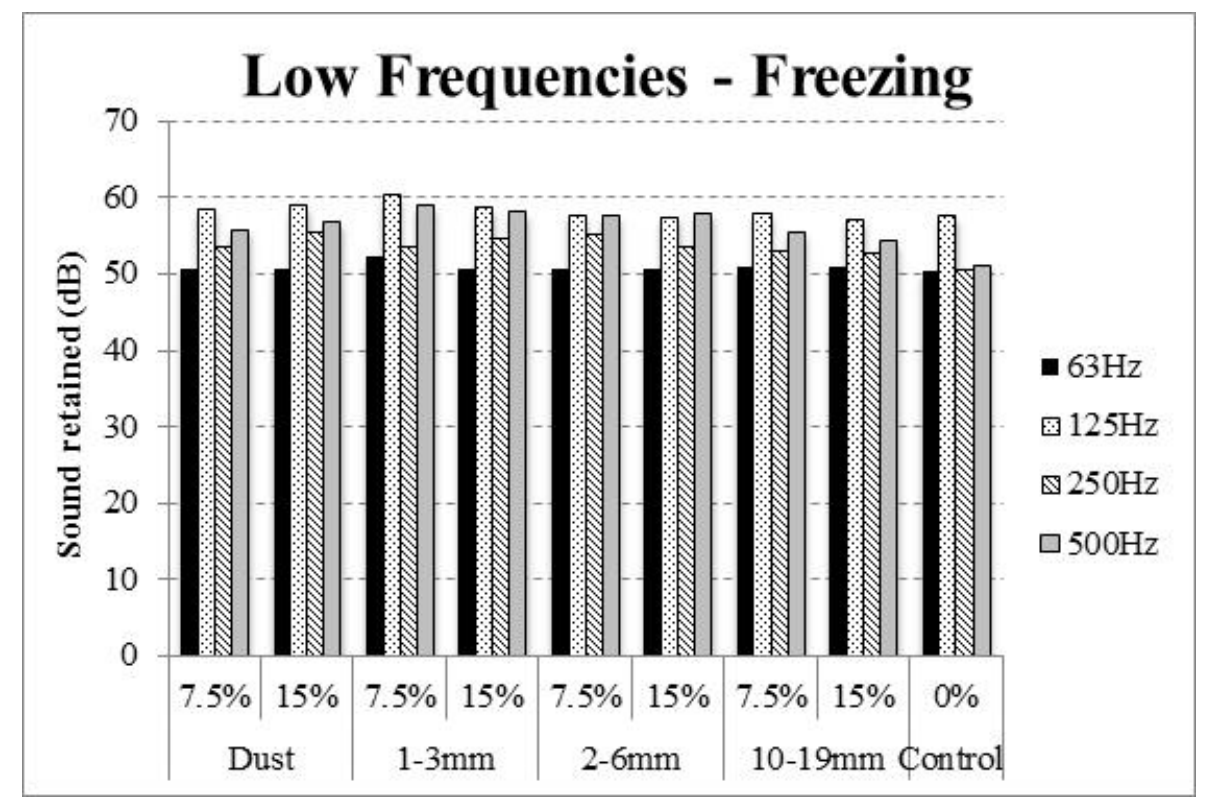

Figure 17 Sound insulating results with low frequencies following freezing 


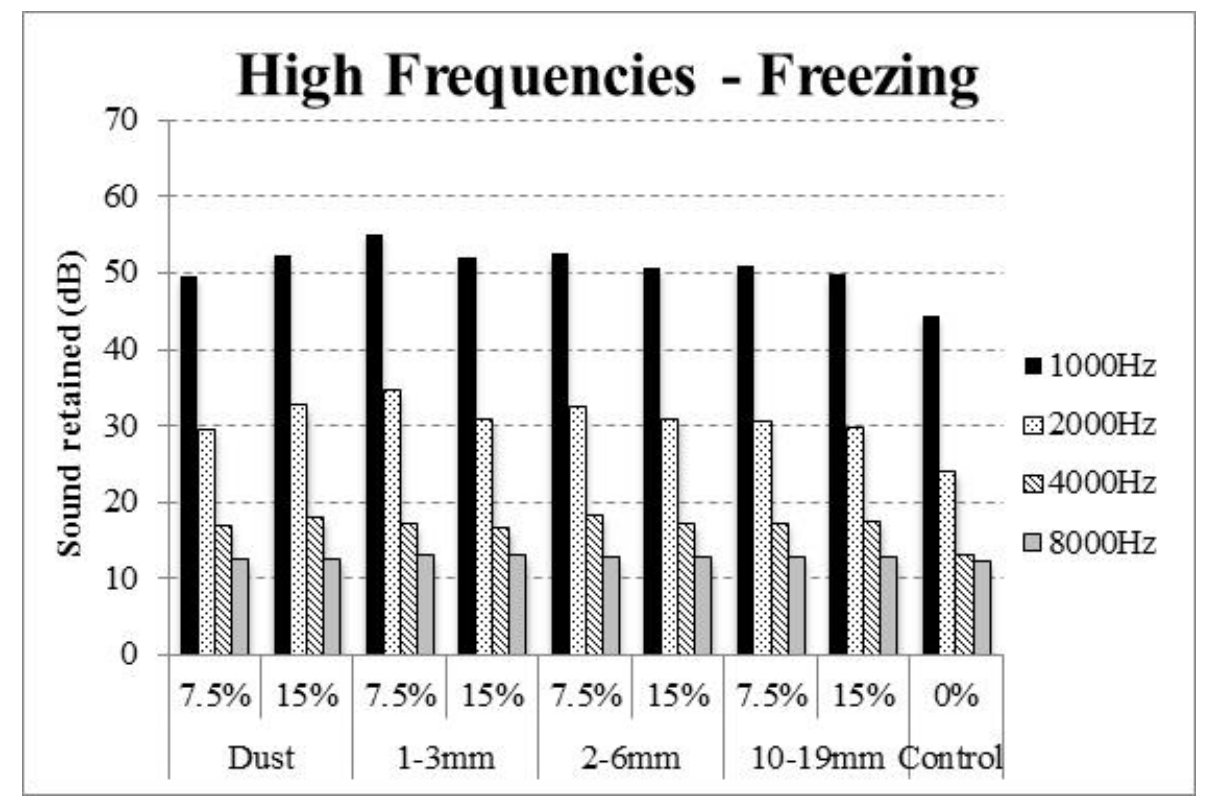

Figure 18 Sound insulating results with high frequencies following freezing 


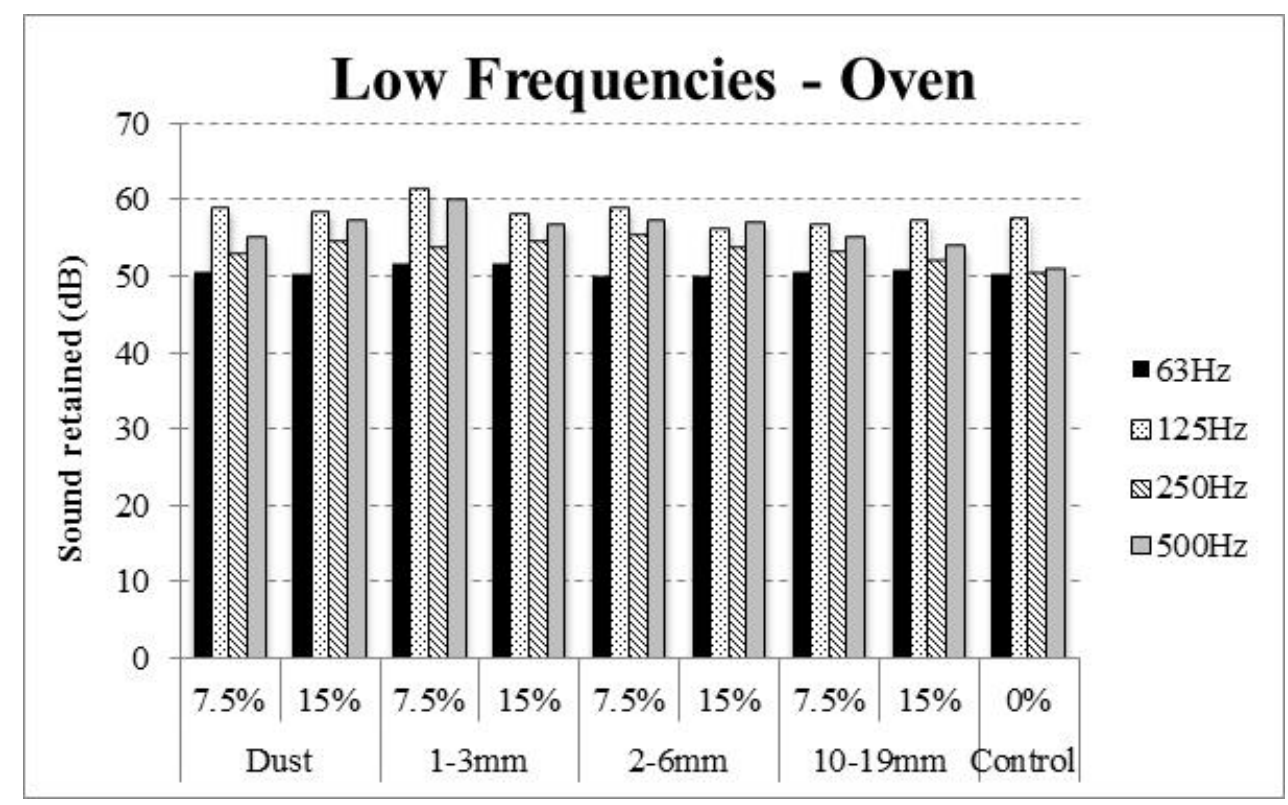

Figure 19 Sound insulating results from low frequency following heating 


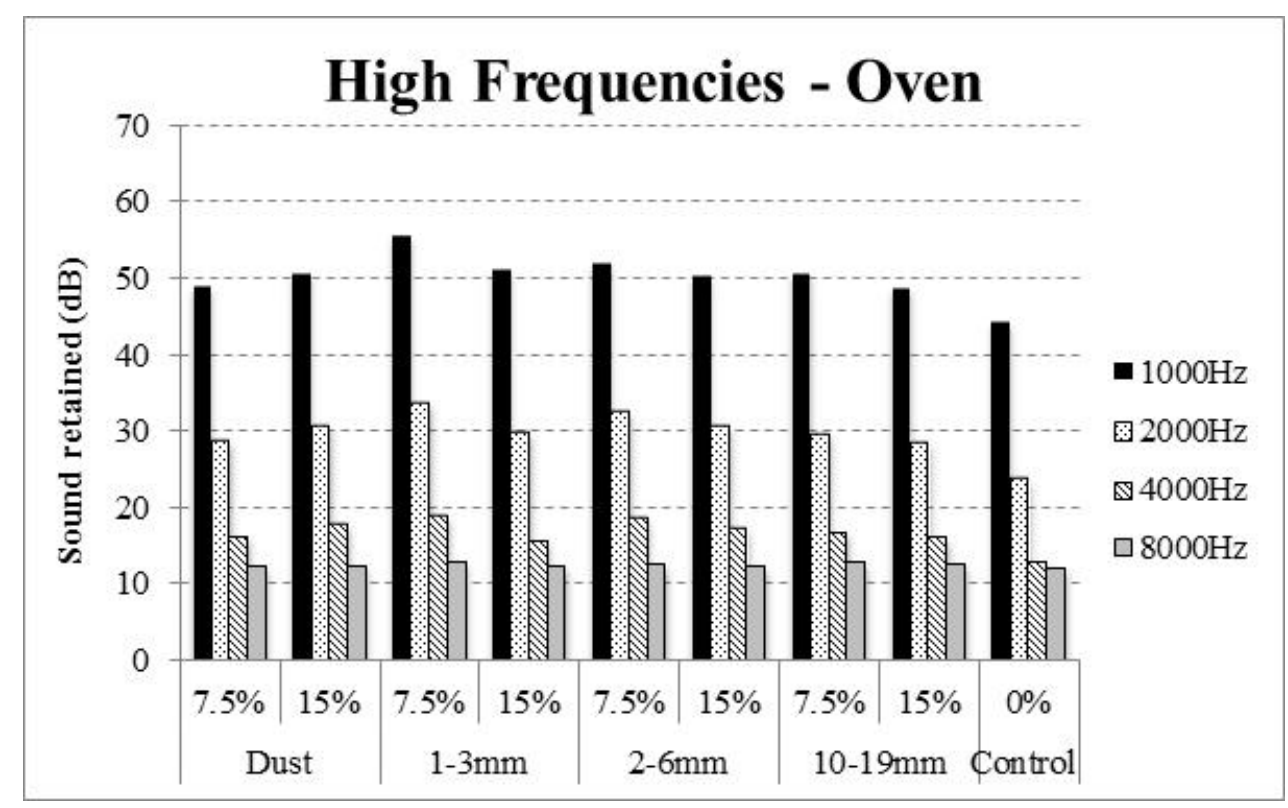

Figure 20 Sound insulating results from high frequency following heating 

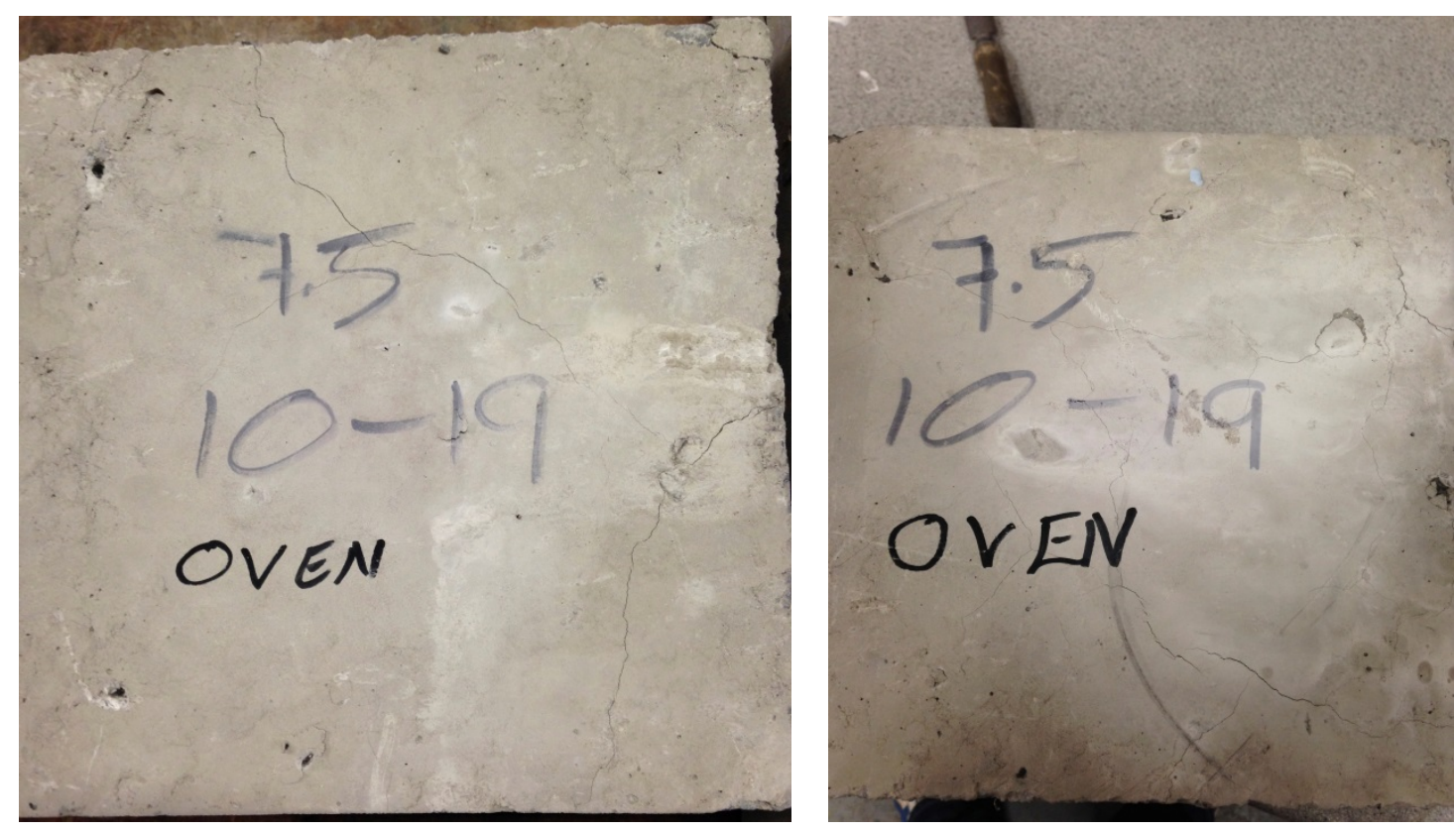

Figure 21 Minor surface cracking observed on the 10-19mm CRC samples following heating 


\section{LIST OF TABLES}

Table 1 Average absorption coefficients for common construction materials

\begin{tabular}{|l|l|}
\hline Material & Sound absorption co-efficient \\
\hline Concrete & $0.02-0.06$ \\
\hline Unpainted blockwork & $0.02-0.05$ \\
\hline Hardwood & 0.3 \\
\hline
\end{tabular}


Table 2 Summary of concrete cast

\begin{tabular}{|c|c|c|c|}
\hline Mix ID & No. of Panels & $\begin{array}{c}\text { Crumb rubber } \\
\text { grade }\end{array}$ & $\begin{array}{c}\text { Fine aggregate } \\
\text { replacement levels }\end{array}$ \\
\hline $1 \mathrm{~A}$ & 9 & \multirow{2}{*}{ Dust } & 7.5 \\
\hline 1B & 9 & & 15 \\
\hline $1 \mathrm{C}$ & 9 & \multirow{2}{*}{$1-3 \mathrm{~mm}$} & 7.5 \\
\hline $1 \mathrm{D}$ & 9 & & 15 \\
\hline $1 \mathrm{E}$ & 9 & \multirow{2}{*}{$2-6 \mathrm{~mm}$} & 7.5 \\
\hline $1 \mathrm{~F}$ & 9 & & 15 \\
\hline $1 G$ & 9 & \multirow{2}{*}{$10-19 \mathrm{~mm}$} & 7.5 \\
\hline $1 \mathrm{H}$ & 9 & & 15 \\
\hline $2 \mathrm{~A}$ & 9 & None & 0 \\
\hline
\end{tabular}


Table 3 Mix proportions

\begin{tabular}{|c|c|c|c|c|c|c|c|c|c|}
\hline \multirow{3}{*}{$\begin{array}{l}\text { Mix } \\
\text { ID }\end{array}$} & \multicolumn{9}{|c|}{ Mass of Ingredients $\left(\mathrm{kg} / \mathrm{m}^{3}\right)$} \\
\hline & \multirow[t]{2}{*}{ Water } & \multirow{2}{*}{$\begin{array}{c}\text { CEM } \\
\text { I }\end{array}$} & \multirow[t]{2}{*}{ FA } & \multicolumn{2}{|c|}{ CA } & \multirow[t]{2}{*}{ Dust } & \multirow[t]{2}{*}{$1-3 \mathrm{~mm}$} & \multirow[t]{2}{*}{$2-6 \mathrm{~mm}$} & \multirow[t]{2}{*}{$10-19 \mathrm{~mm}$} \\
\hline & & & & $10 \mathrm{~mm}$ & $20 \mathrm{~mm}$ & & & & \\
\hline $1 \mathrm{~A}$ & 225.6 & 475 & 527.3 & 555 & 555 & 42.7 & - & - & - \\
\hline 1B & 225.6 & 475 & 484.5 & 555 & 555 & 85.5 & - & - & - \\
\hline $1 \mathrm{C}$ & 225.6 & 475 & 527.3 & 555 & 555 & - & 42.7 & 0 & - \\
\hline $1 \mathrm{D}$ & 225.6 & 475 & 484.5 & 555 & 555 & - & 85.5 & 0 & - \\
\hline $1 \mathrm{E}$ & 225.6 & 475 & 527.3 & 555 & 555 & - & - & 42.7 & - \\
\hline $1 \mathrm{~F}$ & 225.6 & 475 & 484.5 & 555 & 555 & - & - & 85.5 & - \\
\hline $1 \mathrm{G}$ & 225.6 & 475 & 527.3 & 555 & 555 & - & - & - & 42.7 \\
\hline $1 \mathrm{H}$ & 225.6 & 475 & 484.5 & 555 & 555 & - & - & - & 85.5 \\
\hline $2 \mathrm{~A}$ & 225.6 & 475 & 570 & 555 & 555 & - & - & - & - \\
\hline
\end{tabular}

FA - Fine aggregate, CA - Course Aggregate 